\title{
Wind-induced leaf transpiration
}

\author{
Cheng-Wei Huang a, ${ }^{\mathrm{a},}$, Chia-Ren Chu ${ }^{\mathrm{b}}$, Cheng-I Hsieh ${ }^{\mathrm{c}}$, Sari Palmroth ${ }^{\mathrm{a}, \mathrm{d}}$, Gabriel G. Katul ${ }^{\mathrm{a}, \mathrm{e}}$ \\ ${ }^{a}$ Nicholas School of the Environment, Duke University, Durham, North Carolina, USA. \\ ${ }^{b}$ Department of Civil Engineering, National Central University, Taoyuan, Taiwan. \\ ${ }^{c}$ Department of Bioenvironmental Systems Engineering, National Taiwan University, No. 1, Section 4, Roosevelt Road, \\ Taipei 10617, Taiwan. \\ ${ }^{d}$ Department of Forest Ecology and Management, Swedish University of Agricultural Sciences, SE-901 83, Umeå, \\ Sweden \\ ${ }^{e}$ Department of Civil and Environmental Engineering, Duke University, Durham, North Carolina, USA.
}

\begin{abstract}
While the significance of leaf transpiration $\left(f_{e}\right)$ on carbon and water cycling is rarely disputed, conflicting evidence has been reported on how increasing mean wind speed $(U)$ impacts $f_{e}$ from leaves. Here, conditions promoting enhancement or suppression of $f_{e}$ with increasing $U$ for a wide range of environmental conditions are explored numerically using leaf-level gas exchange theories that combine a stomatal conductance model based on optimal water use strategies (maximizing the 'net' carbon gain at a given $f_{e}$ ), energy balance considerations, and biochemical demand for $\mathrm{CO}_{2}$. The analysis showed monotonic increases in $f_{e}$ with increasing $U$ at low light levels. However, a decline in modeled $f_{e}$ with increasing $U$ were predicted at high light levels but only in certain instances. The dominant mechanism explaining this decline in modeled $f_{e}$ with increasing $U$ is a shift from evaporative cooling to surface heating at high light levels. New and published sap flow measurements for potted Pachira macrocarpa and Messerschmidia argentea plants conducted in a wind tunnel across a wide range of $U\left(2-8 \mathrm{~m} \mathrm{~s}^{-1}\right)$ and two different soil moisture conditions were also employed to assess how $f_{e}$ varies with increasing $U$. The radiative forcing imposed in the wind tunnel was only restricted to the lower end of expected field conditions. At this low light regime, the findings from the wind tunnel experiments were consistent with the predicted trends.
\end{abstract}

Keywords: energy balance; laminar boundary layer; leaf-level gas exchange; optimality hypothesis; wind effects

\section{Introduction}

The global water and carbon cycle sensitivity to stomata predicted by global climate models that employ the Ball-Berry (Ball et al., 1987) or Leuning (Leuning, 1995) stomatal conductance formulation has been convincingly documented (Betts et al., 2007; Cox et al., 2000; Gedney

\footnotetext{
${ }^{*}$ Corresponding author

Email addresses: cheng. wei .huang@duke. edu (Cheng-Wei Huang), crchu@ncu.edu .tw (Chia-Ren Chu), hsieh@ntu. edu.tw (Cheng-I Hsieh), sari .palmroth@duke.edu (Sari Palmroth), gaby@duke. edu (Gabriel G. Katul)

Preprint submitted to Elsevier 
et al., 2006). Likewise, detailed ecosystem models predicting gas exchange between the biosphere and atmosphere are analyzed in terms of their sensitivity to stomatal conductance (Baldocchi et al., 2001; Katul et al., 2012). Since water loss through stomata (i.e., transpiration) to the dry atmosphere is inevitable when $\mathrm{CO}_{2}$ uptake (i.e., assimilation) occurs, how stomata respond to environmental factors has long been an active research area. Environmental factors governing transpiration $\left(f_{e}\right)$ from leaves include, at minimum, atmospheric $\mathrm{CO}_{2}$ concentration $\left(c_{a}\right)$, air temperature $\left(T_{a}\right)$, air relative humidity $(R H)$ or vapor pressure deficit (VPD), photosynthetically active radiation (PPFD), soil moisture (or leaf water potential) and mean wind speed $(U)$ (Monteith, 1965). When surveying the literature encompassing a wide range of ecosystems and environmental conditions, conflicting empirical results on the sign of $\partial f_{e} / \partial U$ emerged (Bladon et al., 2006; Campbell-Clause, 1998; Chu et al., 2009; Dixon and Grace, 1984; Grace, 1974; Grace et al., 1975; Grace and Russell, 1982; Gutiérrez et al., 1994; Huang et al., 2010; Hunt et al., 1967; Kim et al., 2014; Martin and Clements, 1935; Zalesny Jr et al., 2006). Positive, negative or week dependency of $f_{e}$ on $U$ for numerous forested canopies has been highlighted and discussed elsewhere (Kim et al., 2014). This is perhaps not surprising and has been foreshadowed by Monteith (1965) who pointed out that wind effects on $f_{e}$ are a vexing problem because of their non-monotonic effects. The thickness of the laminar boundary layer pinned to a leaf surface, which monotonically depends on $U$, determines the diffusive path length for the exchanges of gases between the leaf surface and the turbulent atmosphere above the laminar boundary layer. However, $U$ also dictates the heat exchange between leaves and the overlying atmosphere as well as the degree of evaporative cooling experienced at the leaf surface depending on the radiation load.

The Penman-Monteith (PM) equation that utilizes an energy balance has been extensively used to predict $f_{e}$ for more than 50 years in hydrology. The dependence of $f_{e}$ on $U$ was discussed in the original work describing the PM equation, indicating that the sign of $\partial f_{e} / \partial U$ is mainly governed by a competition between evaporative cooling and surface heating (or cooling). However, the biotic controls for water transport through the stomatal pathway (i.e., encoded as stomatal conductance $g_{s}$ here) remain weakly dependent on $U$ in the PM equation. To be clear, gas exchange through stomata of biologically active scalars is a complex problem given the biotic controls imposed by guard cells. The stomatal pathway serves as the main conduit for $\mathrm{CO}_{2}$ and water vapor exchange, but this pathway can be further impacted by the laminar boundary layer (see Figure 1). Thus, the main objective of this work is to disentangle wind effects from other exogenous environmental factors (e.g., radiative cooling) on $g_{s}$ and $f_{e}$ so as to explore the manifold of possible conditions promoting $\partial f_{e} / \partial U$ to reverse from $>0$ to $<0$ with increasing $U$.

When analyzing responses of stomata to their environment, temperature, atmospheric $\mathrm{CO}_{2}$ concentration and water vapor pressure at the leaf surface are commonly assumed to be sufficiently close to their counterparts in the atmosphere represented by their states beyond the outer edge of the laminar boundary layer. A plausible argument for this approximation is that the thickness of the laminar boundary layer pinned to a leaf is sufficiently small so that the leaf is presumed to be 'well-coupled' to its environment. This approximation is common when interpreting leaf-gas exchange measurements in cuvettes where the flow rate through the chamber is sufficiently large to ensure the validity of the 'well-coupled' approximation. This approximation becomes also convenient when deriving relations between $g_{s}$ and external environmental conditions (Gates, 1968). Following this 'approximation', only monotonic increase in $f_{e}$ with increasing $U$ (i.e., $\partial f_{e} / \partial U>0$ for increasing $U$ ) is expected primarily due to the reduced thickness of the laminar boundary layer. Because measurements (e.g., $g_{s}$ ) within such thin and disturbed laminar boundary layer adjacent to the leaf experiencing variable $U$ are difficult to conduct, a 
leaf-level gas exchange model is needed and developed here for computing mass transfer of $\mathrm{CO}_{2}$ and water vapor. The model combines biochemical demand for $\mathrm{CO}_{2}$ as described by the Farquhar photosynthesis model (Farquhar et al., 1980) for C3 plants, a Fickian mass transfer including transfer through the laminar boundary layer that may be experiencing forced or free convection depending on $U$ and the radiation load, an optimal leaf water use strategy that maximizes 'net' carbon gain for a given $f_{e}$ describing stomatal aperture variations, and a leaf-level energy balance to accommodate evaporative cooling. Hence, the proposed model is able to bridge the gap between biological controls through stomata and the aerodynamic modifications due to $U$ as may be experienced in natural settings. These calculations can be used to arrive at a closed set of equations that predict $f_{e}$ through $g_{s}$ as impacted by variable $U$. The manifold of conditions promoting the sign reversal of $\partial f_{e} / \partial U$ with increasing $U$ can therefore be numerically delineated.

To address this study objective, the manuscript is organized as follows. The model development is first presented in Section 2.1 and Section 2.2 featuring the mass transfer equations for water and carbon dioxide gases through stomates and through the laminar boundary layer. The Farquhar photosynthesis model applied to the mesophyll and the energy balance at the leaf surface are then presented in Section 2.3 and Section 2.4, respectively and then coupled to the mass transfer equations. The optimality hypothesis for stomatal aperture variations with variations in environmental conditions, which is used to mathematically close the overall set of equations for the model system, is discussed in Section 2.5. Other 'closure' conditions for stomatal aperture variations such as those widely used in land-surface schemes (e.g. a Ball-Berry or Leuning type closure) are briefly presented and elaborated on in an appendix. The goal of exploring these alternative and widely used stomatal conductance models is to highlight the non-linearities in $\partial f_{e} / \partial U$ with increasing $U$ in such $g_{s}$ model closure. A broad range of environmental conditions (mainly PPDF, soil moisture, and atmospheric humidity) are then explored in Section 3.1.1-3.1.4 using the proposed model so as to unfold the possible environmental conditions above the laminar boundary layer promoting a sign reversal in $\partial f_{e} / \partial U$ from $>0$ to $<0$. Because the work here employs published and recent wind tunnel experiments on potted plants aimed at discerning the effects of $U$ on measured $f_{e}$, these experimental conditions and the parameters required in model calculations are used as a case study for the model and are discussed in Section 3.2. The measured dependence of $f_{e}$ on $U$ at low PPFD is presented in Section 3.2.1-3.2.2 using the published and new sap flow measurements conducted for two different potted plants with similar leaf dimensions in the wind tunnel across a wide range of $U$ and for two different soil moisture states. The wind-tunnel setup has been described elsewhere (Chu et al., 2009) and only salient features of the experiment are summarized in Appendix A. Since physiological parameters and total leaf area for the potted plants were not directly measured in these wind tunnel experiments, comparisons between modeled and actual leaf-level $f_{e}$ cannot be directly conducted (discussed later). However, the relative response of the sap flow measurements to $U$ and their comparison to model calculations can be used to illustrate the behavior of $f_{e}$ with varying $U$ when all other external conditions are set.

\section{Theory}

The notation and units used throughout are listed in Appendix B and the mass exchange processes at the leaf scale are featured in Figure 1. It is assumed that the state variables such as air temperature, $\mathrm{CO}_{2}$ and water vapor concentrations above the laminar boundary layer (denoted as the turbulent region) are 'well-mixed' and their vertical variations relative to those experienced 
across the laminar boundary layer are small. The energy driving the system is generated through but decays to zero (i.e. no slip) at the leaf surface over a distance defining the laminar boundary layer thickness. The analysis only applies after steady-state conditions in $U$ and $f_{e}$ are attained.

\subsection{Fickian mass transfer}

A two layer mass transport model describing the simultaneous transfer of $\mathrm{CO}_{2}$ and water vapor across the sub-stomatal cavity and the laminar boundary layer attached to the leaf surface (see Figure 1) is given as

$$
\begin{aligned}
& f_{c}=g_{t, \mathrm{CO}_{2}}\left(c_{a}-c_{i}\right) \\
& f_{e}=g_{t, H_{2} O}\left(e_{i}-e_{a}\right),
\end{aligned}
$$

where $f_{c}$ is the $\mathrm{CO}_{2}$ flux, $f_{e}$ is, as before, the water vapor flux, $c_{a}$ is ambient (or external) and $c_{i}$ is the inter-cellular $\mathrm{CO}_{2}$ concentration, $e_{a}$ is ambient (or external) and $e_{i}$ is inter-cellular water vapor pressures, $g_{t, \mathrm{CO}_{2}}$ and $g_{t, \mathrm{H}_{2} \mathrm{O}}$ are the total conductances at the 'leaf scale' for $\mathrm{CO}_{2}$ and water vapor, respectively. Here, storage effects in the leaf and laminar boundary layer are assumed to be small or negligible so that the same mass fluxes cross the stomata and the laminar boundary layers at steady state. Also, turbulent conditions away from the laminar boundary layer prevail thereby allowing variations in $c_{a}$ and $e_{a}$ to be ignored far from the outer edge of the leaf boundary layer as earlier noted. The $g_{t, \mathrm{CO}_{2}}$ and $g_{t, \mathrm{H}_{2} \mathrm{O}}$ can be formulated as

$$
\begin{aligned}
g_{t, \mathrm{CO}_{2}} & =\frac{g_{s, \mathrm{CO}_{2}} g_{b, \mathrm{CO}_{2}}}{g_{s, \mathrm{CO}_{2}}+g_{b, \mathrm{CO}_{2}}} \\
g_{t, \mathrm{H}_{2} \mathrm{O}} & =\frac{\left(g_{s, \mathrm{H}_{2} \mathrm{O}}+g_{\text {res }}\right) g_{b, \mathrm{H}_{2} \mathrm{O}}}{g_{s, \mathrm{H}_{2} \mathrm{O}}+g_{\text {res }}+g_{b, \mathrm{H}_{2} \mathrm{O}}}
\end{aligned}
$$

where $g_{s, \mathrm{CO}_{2}}$ and $g_{s, \mathrm{H}_{2} \mathrm{O}}\left(\approx 1.6 g_{s, \mathrm{CO}_{2}}\right)$ are respectively the stomatal conductance to $\mathrm{CO}_{2}$ and water vapor (Jones, 1992), $g_{\text {res }}$ is the 'residual conductance', and $g_{b, \mathrm{CO}_{2}}$ and $g_{b, \mathrm{H}_{2} \mathrm{O}}$ are respectively the boundary layer conductance for $\mathrm{CO}_{2}$ and water vapor including both forced and free convection. These boundary layer conductances can be determined from $U$ and temperature difference $(\delta T)$ between the leaf surface $\left(T_{s}\right)$ and the atmosphere away from the laminar boundary layer $\left(T_{a}\right)$ as well as the characteristic dimension of the leaf $(d)$ as described elsewhere (Campbell and Norman, 1998). To determine $f_{e}$ and $f_{c}, g_{t, \mathrm{CO}_{2}}$ and $g_{t, \mathrm{H}_{2} \mathrm{O}}$ are required. The following sections describe the determination of $g_{b, i}$ (that varies with $U$ and $\delta T=T_{s}-T_{a}$ ) and $g_{s, i}$ where $i$ refers to $\mathrm{CO}_{2}, \mathrm{H}_{2} \mathrm{O}$ or sensible heat $(H)$. As shown by several experiments (Dawson et al., 2007; Caird et al., 2007; Novick et al., 2009), nocturnal transpiration need not be zero and can be attributed to a combined effect of water loss from stomata (minor leakage from guard cells) and cuticle. This additional water loss typically constitutes $10-30 \%$ of daily transpiration but is not regulated by the biochemical demand of $\mathrm{CO}_{2}$. Thus, $g_{\text {res }}$ in Equation (2) must be interpreted as the sum of night-time (i.e., modeled by setting PPFD=0) stomatal $g_{\text {night }}$ and cuticular $g_{\text {cut }}$ conductance without distinguishing between them. Equation (2) also assumes that the mesophyll conductance to $\mathrm{CO}_{2}$ is much larger than its stomatal counterpart though these mesophyll effects can be included if known (e.g., Volpe et al. (2011)). Hence, when using equation (1), a point of departure from previous models is that well-coupled conditions between the leaf and the atmosphere (i.e., $f_{c} \approx g_{s, \mathrm{CO}_{2}}\left(c_{a}-c_{i}\right)$ and $\left.f_{e} \approx g_{s, \mathrm{H}_{2} \mathrm{O}} \mathrm{VPD}\right)$ are not assumed as the laminar boundary layer thickness changes with changing $U$ as well as leaf surface heating or cooling. It is for this reason 
that previous models using this approximation predict only increasing $f_{e}$ with increasing $U$ and

\subsection{Boundary layer conductances for heat and mass transfer in forced and free convection}

For heat and mass transfer within the laminar boundary layer adjacent to the leaf surface, the combined effects of forced and free convection can be expressed as:

$$
g_{b, i}=1.4 g_{b, i, \text { forced }}+g_{b, i, f r e e}
$$

where $g_{b, i}$ is the boundary layer conductance, $g_{b, i, f o r c e d}$ and $g_{b, i, \text { free }}$ are respectively the forced and free convection conductances. The factor of 1.4 is adopted for naturally turbulent flow as suggested elsewhere (Campbell and Norman, 1998). Through the connection to $U, d$ and $\delta T$ (the temperature difference across the laminar boundary layer reflecting $T_{s}-T_{a}$ ), the empirical formulations of $g_{b, H, \text { forced }}$ and $g_{b, H, \text { free }}$ are given as (Campbell and Norman, 1998):

$$
\begin{aligned}
& g_{b, H, \text { forced }}=\frac{0.664 \rho D_{H} \operatorname{Re}^{1 / 2} \operatorname{Pr}^{1 / 3}}{d}, \\
& g_{b, \text { free }}=\frac{0.54 \rho D_{H}(G r P r)^{1 / 4}}{d},
\end{aligned}
$$

where $\rho$ is the mean air molar density, $D_{H}$ is the thermal diffusivity, $R e=(U d) / v$ is the Reynolds number, where $v$ is the air kinematic viscosity, $\operatorname{Pr}=v / D_{H}$ is the Prandtl number, and $G r=\left(g d^{3} \delta T\right)\left[\left(T_{a}+273.15\right) v^{2}\right]$ is the Grashof number, where $g$ is the gravitational acceleration. The forced and free convection conductances for $\mathrm{CO}_{2}$ and water vapor can be determined by substituting $D_{H}$ and $\operatorname{Pr}$ in Equation (4) with their molecular diffusivity $D_{i}$ and Schmidt number $S_{c}$, respectively. A leaf-level energy balance (see Section 2.4) is now required to determined the unknown variable $T_{s}$ (or $\delta T$ ).

\subsection{Farquhar photosynthesis model}

For $\mathrm{C} 3$ species, the biochemical demand for $\mathrm{CO}_{2}$ is commonly described by the $\mathrm{C} 3$ photosynthesis model (Farquhar et al., 1980). Here, this biochemical demand is approximated by a hyperbolic function reflecting the co-limitations of Rubisco activity and ribulose-1,5biphosphate (RuBP) regeneration rate (and hence electron transport) on photosynthesis and is given as (Vico et al., 2013):

$$
\begin{aligned}
f_{c} & =\frac{k_{1}\left(c_{i}-\Gamma^{*}\right)}{k_{2}+c_{i}}-R_{d} \\
k_{1} & =\frac{J}{4} \\
k_{2} & =k_{1} \frac{a_{2}}{V_{c, \text { max }}}
\end{aligned}
$$

where $k_{1}$ and $k_{2}$ are associated with the photosynthetic parameters, $\Gamma^{*}$ is the $\mathrm{CO}_{2}$ compensation point in the absence of mitochondrial respiration, $R_{d}$ is the daytime mitochondrial respiration rate, $J$ is the electron transport rate that varies with PPFD and the light saturated rate of electron transport $\left(J_{\max }\right)$ as described elsewhere (Medlyn et al., 2002; Vico et al., 2013), $a_{2}=K_{c}\left(1+C_{o a} / K_{o}\right)$, where $K_{c}$ and $K_{o}$ are the Michaelis constants for $\mathrm{CO}_{2}$ fixation and oxygen 
inhibition and $C_{o a}$ is the ambient oxygen concentration, and $V_{c, \max }$ is the maximum carboxylation capacity. A feature of this representation is that the abrupt transition between Rubisco-limited and RuBP-limited photosynthesis is bypassed without requiring an additional ad hoc curvature parameter. This form of the biochemical demand for $\mathrm{CO}_{2}$ ensures that at low $c_{i}, V_{c, \text { max }}$ appreciably controls photosynthesis. Conversely, at large $c_{i}, J_{\text {max }}$ limits photosynthesis. The parameters of the biochemical demand model and their temperature adjustments are summarized in Table 1. Combining Equations (1) and (5), $c_{i}$ and $f_{c}$ can be expressed as a function of $g_{t, \mathrm{CO}_{2}}$ and photosynthetic parameters using (Katul et al., 2010):

$$
\begin{aligned}
& \frac{c_{i}}{c_{a}}=\frac{1}{2}+\frac{1}{2 g_{t, C O_{2}} c_{a}}\left[-k_{1}-k_{2} g_{t, \mathrm{CO}_{2}}+R_{d}\right. \\
& \left.+\sqrt{\left[k_{1}+\left(k_{2}-c_{a}\right) g_{t, C O_{2}}-R_{d}\right]^{2}-4 g_{t, C O_{2}}\left(-c_{a} g_{t, C O_{2}} k_{2}-k_{2} R_{d}-k_{1} \Gamma^{*}\right)}\right]
\end{aligned}
$$

and

$$
\begin{aligned}
& f_{c}=\frac{1}{2}\left[k_{1}+\left(k_{2}+c_{a}\right) g_{t, \mathrm{CO}_{2}}+R_{d}\right. \\
& \left.-\sqrt{\left[k_{1}+\left(k_{2}-c_{a}\right) g_{t, \mathrm{CO}_{2}}-R_{d}\right]^{2}-4 g_{t, \mathrm{CO}_{2}}\left(-c_{a} g_{t, C O_{2}} k_{2}-k_{2} R_{d}-k_{1} \Gamma^{*}\right)}\right] .
\end{aligned}
$$

where the net radiation $\left(Q_{n}\right)$ is computed from the difference between the absorbed radiation $\left(Q_{a b s}\right)$ and emitted longwave radiation $\left(Q_{\text {out }}\right)$ balanced by $H$ and latent heat $(L E)$ fluxes on the leaf surface, $\epsilon_{s}$ is the leaf surface emissivity, $\sigma$ is the Stefan-Boltzmann constant, $c_{p}$ is the specific heat capacity of dry air at constant pressure, $L$ is the latent heat of vaporization of water, $g_{b, H}$ is the boundary layer conductance for heat in forced and free convection (see Section 2.2), and $P_{a}$ is the atmospheric pressure. The $Q_{a b s}$ can be determined from PPFD measurements assuming a constant ratio of all-wave $Q_{a b s}$ to incident PPFD as suggested elsewhere (Green et al., 1995). The $T_{s}$ is now computed as:

$$
T_{s}=T_{a}+\frac{Q_{a b s}-\epsilon_{s} \sigma\left(T_{s}+273.15\right)^{4}-L g_{t, H_{2} O}\left(e_{i}-e_{a}\right) / P_{a}}{6^{c_{p} g_{b, H}}}
$$


where $e_{i} \approx e^{*}\left(T_{s}\right)$ given that the water vapor pressure in the inter-cellular air space is nearly saturated at temperature $T_{i}=T_{s}$ (see Figure 1). It is to be noted that $T_{s}$ is determined here without invoking any linearization, which is a departure from the assumptions used in the original PM derivation. However, a numerical scheme for solving $T_{s}$ is now required as $T_{s}$ is retained on the right hand side of Equation (9) (also embedded in $g_{t, H_{2} O}$ and $g_{b, H}$ ). Equations (8) and (9) again show the significance of the aerodynamic modifications introduced by $U$ through $g_{b, i}$ contributing to $H$ (or $T_{s}$ ) and $L E$. Also, the derivation here assumes that $g_{b, i}>0$, which necessitates a $U>0$. The partitioning of the leaf energy balance to $H$ or $L E$ is also connected to the biochemical demand for $\mathrm{CO}_{2}$ and optimal water use (discussed later) as shown in Section 2.1 and Section 2.5.

\subsection{Optimality hypothesis for stomatal aperture variations}

To close the system of equations, a number of models have been proposed as independent expressions for $g_{s, \mathrm{CO}_{2}}$ (see review by Damour et al. (2010)). Here, an optimality hypothesis (Berninger and Hari, 1993; Cowan and Farquhar, 1977; Givnish and Vermeij, 1976; Hari et al., 1986; Konrad et al., 2008) that uses the economics of leaf-gas exchange is selected in lieu of the widely used Ball-Berry (Ball et al., 1987) (superscripted as BB) or Leuning (Leuning, 1995) (superscripted as LEU) semi-empirical models. According to this hypothesis, the short-term regulation of stomatal aperture is achieved by maximizing carbon gain constrained by water availability or water loss (i.e., $f_{e}$ ). This constrained optimization is mathematically equivalent to an unconstrained optimization problem using an objective function (or Hamiltonian) defined as

$$
h_{a}\left(g_{s, C O_{2}}\right)=f_{c}-\lambda f_{e},
$$

where the species-specific cost of water parameter $\lambda$ is known as the marginal water use efficiency and measures the cost to the plant of loosing water in carbon units thereby bridging the carbon and water economies of the plant. Mathematically, $\lambda$ is the Lagrange multiplier for the unconstrained optimization problem. Assuming $\lambda$ is approximately constant on time scales commensurate with stomatal aperture fluctuations but it can vary on longer time scales (Manzoni et al., 2013), the optimal $g_{s, \mathrm{CO}_{2}}$ can be determined by setting

$$
\frac{\partial h_{a}\left(g_{s, \mathrm{CO}_{2}}\right)}{\partial g_{s, \mathrm{CO}_{2}}}=\frac{\partial f_{c}}{\partial g_{s, \mathrm{CO}_{2}}}-\lambda \frac{\partial f_{e}}{\partial g_{s, \mathrm{CO}_{2}}}=0,
$$

with $\lambda=\left(\partial f_{c} / \partial g_{s, \mathrm{CO}_{2}}\right) /\left(\partial f_{e} / \partial g_{s, C O_{2}}\right)=b^{2}>0$, where $b$ is constant over time scale over which $g_{s, \mathrm{CO}_{2}}$ rapidly varies. Formulated in this manner, $g_{s, \mathrm{CO}_{2}}$ must be 'numerically' computed. Analytical formulation for $g_{s, \mathrm{CO}_{2}}$ can be derived when additional assumptions are proposed including $g_{t, \mathrm{CO}_{2}} \approx g_{s, \mathrm{CO}_{2}}$ or when $g_{b, \mathrm{CO}_{2}} \gg g_{s, \mathrm{CO}_{2}}$ and the leaf is well coupled to the atmosphere as proposed elsewhere (Katul et al., 2010) and shown in Appendix C. Upon further assumption of a constant long-term $c_{i} / c_{s}$ and a linearized biochemical demand function, the analytical form of $g_{s, \mathrm{CO}_{2}}$ derived from the optimality hypothesis has been shown to be identical to BB and LEU (see Appendix D) except for the reduction function of VPD or $R H$ (Katul et al., 2012). When exploring the manifold of possible conditions promoting $\partial f_{e} / \partial U$ to reverse from $>0$ to $<0$ with increasing $U$, the $\mathrm{BB}$ and LEU formulations are also employed instead of the optimality hypothesis and the outcomes of these calculations are presented separately in Appendix D but highlighted in the results section.

As shown in Figure 2, a numerical solution is now required to determine $g_{s, C O_{2}}$ and $T_{s}$ as well as $f_{c}, f_{e}$, and $H$ for a given set of external variables $U, P a$, PPFD, $Q_{a b s}, T_{a}, e_{a}$ (or $\left.R H\right), c_{a}$ and 
leaf dimension $d$, given that the laminar boundary layer may play a significant role on leaf-level gas exchange. The following parameters are need to conduct the model calculations: $V_{c, \max }$, $J_{\max }, \lambda$ and $\epsilon_{s}$. The analysis here also assumed that $\partial g_{\text {res }} / \partial g_{s, \mathrm{CO}_{2}}=0$ thereby necessitating an independent estimate of $g_{\text {res }}$ to complete the mathematical description as earlier noted.

\section{Results and discussions}

To address the study objective, four scenarios are examined through model calculations to explore the effects of soil water availability and evaporative demand on leaf-level gas exchange across a wide range of wind speed and light availability. These scenarios are for (1) wellwatered soil conditions with small evaporative demand, (2) water-stressed soil conditions with small evaporative demand, (3) large evaporative demand under well-watered soil moisture conditions and (4) large evaporative demand under water-stressed soil moisture conditions. These model results are then contrasted with sap flow velocity measurements for a wide range of $U$ but two different soil moisture states reported in previous wind-tunnel experiments (Chu et al., 2009) and a recent one with a similar configuration described in Appendix A. A drawback in these experiments is that the artificial light used to generate a steady PPFD in the wind-tunnel experiments only corresponds to a low value encountered in natural settings (about a factor of 5-6 lower than the maximum theoretical PPFD for clear-sky conditions).

\subsection{Model analysis illustrating a decreasing $f_{e}$ with increasing $U$}

Prior to discussing the effects of $U$ on leaf-level gas exchange, the difference between the 'actual' evaporative demand and evaporative demand approximated by VPD requires clarification. The VPD is the difference between actual and saturated water vapor pressure in the atmosphere (i.e., $\left.\mathrm{VPD}=e_{a}{ }^{*}\left(T_{a}\right)-e_{a}=e_{a}{ }^{*}\left(T_{a}\right)(1-R H)\right)$, where $e_{a}{ }^{*}\left(T_{a}\right)$ is the saturated water vapor pressure at a given ambient temperature outside the laminar boundary layer and can be determined from atmospheric $R H$ and $T_{a}$. However, VPD may substantially deviate from the 'actual' evaporative demand (i.e., $e_{i}-e_{a}$ ), which is impacted by wind speed above the leaf surface (see Figure 1). The deviation between these two evaporative demands increases when the leaf becomes 'decoupled' from the atmosphere (i.e., $T_{s} \neq T_{a}$ and thus $e_{i} \neq e_{a}{ }^{*}\left(T_{a}\right)$ ) as expected. For the purposes here, VPD (or $R H$ ) outside the laminar boundary layer is used to define the dryness of the atmosphere because this measure is not sensitive to $U$ and because it is commonly 'imposed' on the canopy by much larger scale meteorological conditions. The $R H=60 \%$ and $20 \%$ were respectively set for small and large atmospheric evaporative demand in model calculations. The PPFD range explored here is selected to be within the expected range of diurnal variations observed in field conditions. All other environmental factors (i.e., $T_{a}=25{ }^{\circ} \mathrm{C}, c_{a}=400 \mathrm{ppm}$ and $P_{a}=101.3$ $\mathrm{kPa}$ ), physiological parameters (i.e., $V_{c \max , 25}$ and $J_{\max , 25}$ are respectively 50 and $100 \mu \mathrm{mol} \mathrm{m}^{-2}$ $\mathrm{s}^{-1}$, which are well within the range in a literature survey encompassing more than 100 species (Wang et al., 1996; Wullschleger, 1993)), leaf attributes (i.e., $d=0.015 \mathrm{~m}$ ) and $\epsilon_{s}=0.95$ are maintained constant. It should be noted that the overall features for the following discussions (i.e., Section 3.1.1-3.1.4) associated with the model calculations are not altered by the choice of the two physiological parameters. While a larger value of $\lambda$ is expected for limited soil water availability (Katul et al., 2012; Mäkelä et al., 1996; Manzoni et al., 2011), the values of $\lambda$ selected for well-watered and water-stressed conditions are respectively 0.001 and $5 \mu \mathrm{mol} \mathrm{mol}^{-1} \mathrm{kPa}^{-1}$ to represent two extreme water conditions in the soil. The value of $g_{\text {res }}$ is set to be $0.04 \mathrm{~mol} \mathrm{~m}^{-2} \mathrm{~s}^{-1}$ but the analysis is not sensitive to $g_{\text {res }}$ when it resides in the range from 0.02 to $0.1 \mathrm{~mol} \mathrm{~m}^{-2} \mathrm{~s}^{-1}$ 
(not shown here). This range covers values reported for many species as summarized elsewhere (Caird et al., 2007). The modeled $f_{e}, f_{c}$ and $g_{s, \mathrm{CO}_{2}}$ as well as a number of dimensionless ratios such as the Bowen ratio $(=H / L E)$, leaf flux-based water use efficiency (WUE $\left.=f_{c} / f_{e}\right)$ and $c_{i} / c_{s}$ are shown in Figure 3, 4, 5 and 6 for the four scenarios and for increasing $U$.

\subsubsection{Well-watered conditions with small evaporative demand}

Figure 3 shows that $f_{e}, f_{c}$ and $g_{s, \mathrm{CO}_{2}}$ generally increase with increasing PPFD as expected. How the trend of $f_{e}, f_{c}$ and $g_{s, \mathrm{CO}_{2}}$ is impacted by $U$ clearly varies for different light conditions. Based on the model calculation, $\partial f_{e} / \partial U>0$ at lower PPFD while $\partial f_{e} / \partial U<0$ at higher PPFD. The transition occurs at PPFD $\approx 1550 \mu \mathrm{mol} \mathrm{m}^{-2} \mathrm{~s}^{-1}$ and can be explained by how the energy balance is partitioned between $H$ and $L E$ as $U$ increases. The $\partial f_{e} / \partial U>0$ with increasing $U$ occurs when the Bowen ratio $<0$. For a small Bowen ratio, $H$ further decreases (i.e., $H<0$; surface cooling) with increasing $U$ (i.e., $g_{b, H}$ ) at low PPFD. The model calculations suggest the $H<0$ in the energy balance is an outcome of evaporative cooling and low $R_{n}$. At higher PPFD, increases in $H$ (i.e., $H>0$; surface heating) occur due to rapid increases in $g_{b, H}$ with increasing $U$. This increase in $H$ is mediated by the fact that the difference between $T_{s}$ and $T_{a}$ (i.e. the driving force for $H$ ) tends to diminish with increasing $U$ (see Equation (8)). Not withstanding this compensatory effect arising from a reduced driving force for $H$, the overall increase in $H$ results in a decrease in $L E$. This highlights the main mechanism leading to an apparent decline in $f_{e}$ with increasing $U$. It may be stated that when $H<0, \partial f_{e} / \partial U>0$ for all $U$. However, when $H>0, \partial f_{e} / \partial U<0$ with further increases in $U$.

Similar to $f_{e}$, modeled $f_{c}$ declines at high PPFD but increases at low PPFD with increasing $U$. The transition occurs when PPFD $\approx 1250 \mu \mathrm{mol} \mathrm{m}^{-2} \mathrm{~s}^{-1}$ (i.e., lower than $f_{e}$ ). The increasing trend in $f_{c}$ with increasing $U$ at a low PPFD was also reported elsewhere (Kitaya et al., 2004) for tomato seedlings in a wind-tunnel type chamber. Different from $f_{e}$ and $f_{c}$, a monotonic increase in $g_{s, \mathrm{CO}_{2}}$ with increasing $U$ was maintained across all PPFD in the model calculations. Adopting well-coupled assumption, however, common models assume $g_{s, \mathrm{CO}_{2}}$ only serves as an upper limit for $g_{t, \mathrm{CO}_{2}}$ and remains constant for different $U$ even when the leaf is 'decoupled' from the atmosphere at low wind speed (see Appendix C). The modeled $g_{b, \mathrm{CO}_{2}}$ here is dominated by forced convection (i.e., free convection is negligible) and $g_{b, \mathrm{CO}_{2}} \gg g_{s, \mathrm{CO}_{2}}$ (not shown here), leading to $g_{t, C O_{2}} \approx g_{s, C_{2}}$ and $c_{s} \approx c_{a}$. These results illustrate how variations in $g_{s, C O}$ can be associated with changing $U$ even for well-coupled conditions between leaf and atmosphere. For a given $U$ (i.e., the replenishment rate of $\mathrm{CO}_{2}$ through the laminar boundary layer is fixed), larger $c_{i} / c_{s}$ in the lower PPFD regime can be attributed to smaller assimilation rate so that $c_{i}$ tends to be closer to $c_{s}$ (i.e., the depletion rate of $\mathrm{CO}_{2}$ in the stomatal cavity is low). On the other hand, increasing $c_{i} / c_{s}$ with increasing $U$ at a given PPFD suggests that $g_{s, \mathrm{CO}_{2}}$ promoted by $g_{b, \mathrm{CO}_{2}}$ at higher $U$ resulted in larger replenishment rate of $\mathrm{CO}_{2}$ in the stomatal cavity. Larger flux-based WUE $\left(=f_{c} / f_{e}\right)$ was computed under low $U$ and low PPFD due to faster reductions in $f_{e}$ with decreasing $U$ when compared to $f_{c}$ at low PPFD. This implies that WUE may be larger for leaves within the lower part of a canopy if the physiological, radiative, and aerodynamic characteristics are unaltered (though a less likely scenario given variations in leaf nitrogen content).

\subsubsection{Water-stressed condition with small evaporative demand}

Figure 4 shows trends in $f_{e}, f_{c}$ and $g_{s, \mathrm{CO}_{2}}$ with increasing $U$ for variable PPFD when soil moisture is limiting (i.e., large $\lambda$ ). Modeled $f_{e}$ and $f_{c}$ trends with increasing $U$ agree with their well-watered counterparts but their transitions are now 'shifted' to smaller PPFD $(\approx 1350$ and 
$1150 \mu \mathrm{mol} \mathrm{m}{ }^{-2} \mathrm{~s}^{-1}$ for $f_{e}$ and $f_{c}$, respectively). The transition for $f_{e}$ at a smaller PPFD can be explained again by the larger Bowen ratio due to the smaller $f_{e}$ induced by water-stressed conditions (higher $\lambda$ ). Compared with well-watered conditions (see Figure 3), $g_{s, \mathrm{CO}_{2}}$ is generally smaller. Also, $g_{s, \mathrm{CO}_{2}}$ does not significantly increase with increasing $U$ in low PPFD and even decreases with increasing $U$ in the high PPFD range. Field experiments (Campbell-Clause, 1998) on two grapevine cultivars measured by porometry reported a reduced $g_{s, \mathrm{CO}_{2}}$ with increasing $U$, a pattern consistent with the model results here. Moreover, smaller $c_{i} / c_{s}$ corresponding to a larger $\lambda$ have been predicted for this scenario, which is supported by experiments and other model predictions (Katul et al., 2012; Prentice et al., 2011). In general, $c_{i} / c_{s}$ varies with $g_{s, \mathrm{CO}_{2}}\left(\approx g_{t, \mathrm{CO}_{2}}\right)$ but its dependence on $T_{s}$ in the physiological parameters of Equation (6) complicates its variations with $U$. Thus, modeled $c_{i} / c_{s}$ at the two end members of the light regime (i.e., very low and very high light PPFD) can exhibit non-monotonic variation with increasing $U$. As a consequence, the model results predict enhanced WUE compared to well-watered conditions because $f_{e}$ is reduced more rapidly with increasing $\lambda$ than $f_{c}$. Recall that $f_{c}$ is impacted by another compensatory physiological mechanism (regulating $c_{i}$ ) and optimality conditions tend to maximize $f_{c}$ for a given $f_{e}$. With progressively drying conditions in the soil, similar trends in WUE have been reported elsewhere again lending some support to the model results here (DeLucia and Heckathorn, 1989; Liu et al., 2005; Masle and Farquhar, 1988). This analysis suggests that WUE may increase with some reductions in water supply from the soil volume without significant reductions in plant photosynthesis (and possibly crop yield in some instances).

\subsubsection{Large evaporative demand under well-watered conditions}

The responses of $f_{e}, f_{c}$ and $g_{s, \mathrm{CO}_{2}}$ to smaller $R H$ (i.e., overall 'actual' evaporative demand is larger) under well-watered soil condition are shown in Figure 5. When soil water availability is not limiting leaf transpiration, the effect of enhanced driving force from the atmosphere reduces $g_{s, \mathrm{CO}_{2}}$ monotonically (i.e., $\partial g_{s, \mathrm{CO}_{2}} / \partial \mathrm{VPD}<0$ for all VPD; roughly, $g_{s, \mathrm{CO}_{2}} \sim \mathrm{VPD}^{-1 / 2}$ to a leading order; see Katul et al. (2010)). This finding is consistent with Helox experiments (i.e., helium:oxygen mixture is used as a surrogate to control the 'actual' evaporative demand) reported elsewhere (Mott and Parkhurst, 1991) and forms the basis of the Hamiltonian $H_{a}$. However, reduced $g_{s, \mathrm{CO}_{2}}$ due to larger evaporative demand diminishes $f_{c}$ and $c_{i} / c_{s}$, but $f_{e}$ is enhanced by increased evaporative demand because of the increased driving force (i.e., $f_{e} \sim \mathrm{VPD}^{-1 / 2} \times$ VPD to a leading order). As a result, a decreasing overall WUE with larger evaporative demand emerges. Using leaf gas exchange measurements, the response of $f_{c}$ and $f_{e}$ as well as WUE to increasing evaporative demand for Gossypium hirsutum L. under well-watered condition, explored in glasshouse bays by Duursma et al. (2013), are consistent with the model calculations here. Since $f_{e}$ increases with increasing evaporative demand, the $H$ and Bowen ratio governed by the energy balance are subsequently reduced, leading to a shift in the transition PPFD where $\partial f_{e} / \partial U$ reverses sign with increasing $U$ in a PPFD value well outside the range considered here. For the particular conditions explored here, $\partial f_{e} / \partial U>0$ prevails for all PPFD commonly encountered in ecosystem studies. Evaporative cooling dominates throughout given that surface heating is reduced with increasing $U$ even in high PPFD.

\subsubsection{Large evaporative demand under water-stressed conditions}

Figure 6 shows the trends in $f_{e}, f_{c}$ and $g_{s, \mathrm{CO}_{2}}$ with respect to variable $U$ and PPFD when evaporative demand and soil water availability are simultaneously limiting leaf-level gas exchange with the atmosphere. Compared to the well-watered conditions with large evaporative demand (see Figure 5), a further reduction in $g_{s, \mathrm{CO}_{2}}$ is expected due to limited soil water availability (i.e., 
larger $\lambda$ ). As discussed earlier, the overall decreasing trend in $f_{e}, f_{c}$ and $c_{i} / c_{s}$ can be simply explained by this reduced $g_{s, \mathrm{CO}_{2}}$, given a constant driving force from the atmosphere. Similar to the comparison for small evaporative demand between the two end members of the soil water availability conditions (see Section 3.1.1 and 3.1.2), the more rapid reduction of $f_{e}$ than $f_{c}$ results in enhanced WUE. Interestingly, the transition PPFD responsible for the reversed sign of $\partial f_{e} / \partial U$ emerges again. This is because the corresponding $H$ and Bowen ratio are enhanced with decreasing $L E$ (i.e., $f_{e}$ ) thereby shifting back the transition within the range of PPFD considered here. This transition occurs at PPFD $\approx 1400 \mu \mathrm{mol} \mathrm{m}^{-2} \mathrm{~s}^{-1}$.

To sum up, $\partial f_{e} / \partial U>0$ is generally satisfied for low PPFD. However, $\partial f_{e} / \partial U$ at high PPFD can be positive or negative depending on the driving forces for transpiration (e.g., evaporative demand) and soil water availability (e.g., leaf water status and $\lambda$ ). Figure 7 summarizes $\partial f_{e} / \partial U$ for a wide range of $U$ and typical low and high PPFD, low and high evaporative demand and for two extreme $\lambda$ 's representing different soil water availability. It is to be noted that when replacing the optimal stomatal conductance closure with BB or LEU formulations, qualitatively similar results emerge though the transition points shift to smaller PPFD due to the larger predicted values of $f_{e}$ as shown in Appendix D.

\subsection{Sap flow measurements in a wind tunnel}

To further explore the variations in $\partial f_{e} / \partial U$ with increasing $U$, sapflow velocity $\left(V_{s}\right)$ data reported by Chu et al. (2009) are complemented by recent experiments on the same species and in the same wind tunnel. The experimental setup, the species used, and the soil moisture conditions are reviewed in Appendix A (see also Figure 8). In the experiments here, only whole plant (or branch) steady-state transpiration rate $F_{e}$ derived from $V_{s}$ is available for two species across various $U$ for: nocturnal (or PPFD $=0)$ and low PPFD $\left(=250 \mu \mathrm{mol} \mathrm{m}^{-2} \mathrm{~s}^{-1}\right)$ and for two soil moisture states (well-watered and water-stressed). Steady-state conditions were checked for each prescribed $U$ by waiting until measured $d V_{s} / d t \approx 0$. A major advantage of the wind tunnel setup is that all the leaves experienced steady and uniform $U$ and PPFD permitting direct $f_{e^{-}}$ trend comparison with leaf-level gas exchange model calculations under given conditions. For comparisons with the model results, the focus is on the behavior of $\partial f_{e} / \partial U$ variations. Hence, to facilitate this comparison, measured transpiration rates are normalized using the scaling relation:

$$
\frac{F_{e}}{F_{\text {emax }}}=\frac{V_{s} A_{s}}{V_{s_{\max } A_{s}}}=\frac{f_{e} A_{l}}{f_{e_{\max } A_{l}}}=\frac{V_{s}}{V_{s \max }}=\frac{f_{e}}{f_{e_{\max }}}
$$

where $A_{s}$ and $A_{l}$ are respectively the sapwood and total leaf area, and $F_{e \max }$ and $f_{e_{\max }}$ are $F_{e}$ and $f_{e}$ at maximum wind speed for each set of PPFD and soil moisture conditions. Likewise, the model results are normalized by their $f_{e}$ at maximum wind speed for each PPFD and soil moisture conditions. This normalization is selected because $U$ variations are to be studied while all other conditions are held constant. The normalization for the measurements is expected to be reasonable under steady state conditions as is the case here (see Appendix A) and for a linear relation between $F_{e}$ and $V_{s}$, which was reported by Chu et al. (2009). Recall that a direct comparison between measured and modeled $f_{e}$ (or $F_{e}$ ) cannot be conducted due to the lack of $A_{s}$ and $A_{l}$ measurements as well as leaf-gas exchange parameters. As shown later through model calculations, such normalized $f_{e}$ may be sufficiently adequate to capture plant system responses to $U$ variations, which is the main focus here. Three physiological parameters must be a priori specified before implementing the proposed model: $V_{c \max , 25}, J_{\max , 25}$ and $\lambda$. For all runs, including runs employing the published data from Chu et al. (2009) and the recent wind-tunnel experiments, the 
$V_{c m a x, 25}$ and $J_{\max , 25}$ were taken to be 50 and $100 \mu \mathrm{mol} \mathrm{m}^{-2} \mathrm{~s}^{-1}$ (see Table 1). Though leaf-level gas exchange measurements were not available to infer directly these parameters, a sensitivity analysis showed that when using normalized- $f_{e}$ (i.e. $f_{e}$ normalized by its maximum coinciding with the highest $U$ for model and measurements) for comparisons, modeled normalized- $f_{e}$ was not sensitive to the precise choice of $V_{c \max , 25}$ and $J_{\max , 25}$ (see Appendix E). The values of $\lambda$ used for the two species under different soil water conditions are summarized in Table Appendix A.2. For well-watered conditions (i.e., when the cost of water in carbon units is small), $\lambda=0.001$ $\mu \mathrm{mol} \mathrm{mol}{ }^{-1} \mathrm{kPa}^{-1}$ and is arbitrarily selected. The normalized $f_{e}$ variations with $U$ are again not sensitive to this choice of $\lambda$ provided its value is sufficiently small and finite (Katul et al., 2010) for well-watered soil conditions. However, a larger value of $\lambda$ is expected when soil water availability is limited as mentioned before (see Section 3.1). The $\lambda$ for Pachira macrocarpa and Messerschmidia argentea under water-stressed conditions were determined by fitting modeled to measured normalized- $f_{e}$. The resulting $\lambda$ are respectively 0.85 and $3.5 \mu \mathrm{mol} \mathrm{mol}^{-1} \mathrm{kPa}^{-1}$ for Pachira macrocarpa and Messerschmidia argentea, which are within the range reported for approximately 50 species (Manzoni et al., 2011). It was found that trends in normalized- $f_{e}$ with variable $U$ chiefly depend on $\lambda$ and PPFD once the evaporative demand, $c_{a}$, PPDF, and air temperature are set. Based on these findings, the wind-tunnel comparison presented here only utilizes normalized- $f_{e}$ with pre-specified $V_{c \max , 25}$ and $J_{\max , 25}$ as the goal is to illustrate the low PPFD condition responsible for the positive sign of $\partial f_{e} / \partial U$. For the computation of $g_{b, i}, d$ is assumed to be $0.015 \mathrm{~m}$ for both species and all cases. The trends in the measurements and models for normalized $f_{e}$ are now presented for the published and the more recent wind tunnel experiments.

\subsubsection{Previous wind-tunnel experiments (Chu et al., 2009)}

Where possible, the measured nocturnal (i.e. $\mathrm{PPDF}=0$ ) sap flow in the previous wind-tunnel experiments (Chu et al., 2009) are used for inferring $g_{\text {res }}$ (see discussion in Section 2.1). It is inferred by matching normalized- $f_{e}$ computed from the energy balance to the steady-state sap flow measurement (i.e., no capacitive effects and water refilling the xylem) for various $U$. Furthermore, this $g_{\text {res }}$ is assumed to be independent of $g_{s, H_{2} O}$ so that $\partial g_{\text {res }} / \partial g_{s, H_{2} O}=0$ as noted earlier. Using published data reported elsewhere (Chu et al., 2009), the measured nocturnal $f_{e}$ (i.e. at PPFD $=0$ ) normalized by the maximum nocturnal $f_{e}$ (labeled as $f n_{e, \max }$ ) at maximum $U$ versus the modeled results with the best-fit $g_{\text {res }}=0.04 \mathrm{~mol} \mathrm{~m}^{-2} \mathrm{~s}^{-1}$ is shown in Figure 9(a). The best-fit $g_{\text {res }}$ was determined from a 'global search' that minimizes the root-mean squared percent error $(R M S P E)$ between modeled and measured $f_{e} / f n_{e, \max }$ during conditions where PPFD $=0$. Here, the RMS PE is defined as

$$
R M S P E=\sqrt{\frac{1}{N} \sum_{i=1}^{N} \Delta_{i}^{2}} \times 100,
$$

where $N$ is the number of data points and $\Delta_{i}$ is the difference between measured and modeled $f_{e} / f n_{e, \max }$ computed solely from energy balance considerations. During nighttime (i.e. PPFD $=0$ ), the main external driver responsible for $f_{e}$ variability is variation in $U$ (i.e., $g_{b, H_{2} O}$ ) given that the evaporative demand (i.e., $T_{a}$ and $R H$ ) and $g_{\text {res }}$ are constants and the soil was wellwatered in those published experiments (Chu et al., 2009). The constant $g_{\text {res }}$ here does not imply a constant $f_{e}$ when $U$ increases, and in fact, nocturnal $f_{e}$ does increase with increasing $U$ through $g_{b, H_{2} O}$. It is to be noted that $g_{r e s}=0.04 \mathrm{~mol} \mathrm{~m}^{-2} \mathrm{~s}^{-1}$ is determined only from these prior experiments. The data set described in Appendix A are not used in the inference of $g_{\text {res }}$ as the aforementioned data are all collected at PPFD $=250 \mu \mathrm{mol} \mathrm{m}^{-2} \mathrm{~s}^{-1}$ (i.e. no nocturnal like runs). 
Inserting the best-fit $g_{\text {res }}\left(=0.04 \mathrm{~mol} \mathrm{~m}^{-2} \mathrm{~s}^{-1}\right)$ into the leaf-level gas exchange model described in Section 2, Figure 9 (b) shows reasonable agreement between measured and modeled daytime normalized- $f_{e}$ reported in Chu et al. (2009) for well-watered soil condition for different $U$ at PPFD $=250 \mu \mathrm{mol} \mathrm{m}^{-2} \mathrm{~s}^{-1}$. The $g_{\text {res }}$ only serves as an additional pathway for water vapor transport (but not $\mathrm{CO}_{2}$ ) during daytime. As suggested elsewhere (Caird et al., 2007), no experimental evidence has been presented that shows significant impact of $g_{r e s}$ on $g_{s, \mathrm{CO}_{2}}$ or carbon gain. Additionally, model sensitivity analysis (not shown here) was conducted on $g_{\text {res }}$ demonstrating that $g_{s, \mathrm{CO}_{2}}$ and $f_{c}$ are not sensitive to variations in $g_{\text {res }}$, which only provides a base line value for $f_{e}$ during daytime conditions. The increasing trend in modeled $g_{s, \mathrm{CO}_{2}}\left(\right.$ not $g_{t, \mathrm{CO}_{2}}$ ) with increasing $U$ is presented in Figure 9(c) for the same conditions as those in Figure 9(b). The monotonic increase in $f_{e}$ and $g_{s, \mathrm{CO}_{2}}$ with increasing $U$ occurs at low PPFD reported here, which is consistent with other wind-tunnel studies conducted at low PPFD regimes (Grace, 1974; Grace and Russell, 1982; Hunt et al., 1967; Martin and Clements, 1935).

\subsubsection{Recent wind-tunnel experiments}

For the two species in the present wind-tunnel experiment, the comparison between measured and modeled daytime (i.e. PPFD $=250 \mu \mathrm{mol} \mathrm{m}^{-2} \mathrm{~s}^{-1}$ ) $f_{e}$ normalized by the corresponding maximum daytime $f_{e}$ under two different soil water conditions across a wide range of $U$ is shown in Figure 10. Previous data from Chu et al. (2009) are included only for reference (see Figure 9 (b)). In Figure 10, the arrow indicates the direction of increasing $U$. Similar to Figure 9 (b), the normalized- $f_{e}$ for each species at a given soil water status monotonically increases with increasing $U$ at the low PPFD that is consistent with model predictions. It should be noted again that we do not attempt to conduct a one-to-one comparison between measured and modeled absolute $f_{e}$ given the absence of leaf physiological measurements, leaf area index, and leaf-to-sapwood area. Only trends in measured sap flow velocity at steady-state conditions, when properly normalized, are used for such qualitative comparisons between measured and modeled $f_{e}$ with increasing $U$. To be clear, the recent experiments are employed as independent data sources to show only the increasing trends in $f_{e}$ with increasing $U$ at low PPFD for the two different species and two different soil water availability. Moreover, measured $V_{s}$ (used as a surrogate to $f_{e}$ ) for the two species under water-stressed soil conditions was significantly smaller when compared to their well-watered counterparts. The reductions in $V_{\text {smax }}$ are approximately $20 \%$ and $15 \%$ for Pachira macrocarpa and Messerschmidia argentea, respectively. It is also suggested that the potted plants did sense soil moisture stress even though the drop in the measured water saturation is only $10 \%$ (see Table Appendix A.2) between well-watered and water-stressed conditions. To sum up, these comparisons suggest that the proposed model reasonably recovers the patterns reported in the wind tunnel experiment for steady low PPFD and quasi-steady soil moisture states and across a wide range of wind speeds.

\subsection{Study limitation}

Given all the assumptions made to arrive at the model and the $f_{e}$-trend comparison between modeled and measured results, it is instructive to recapitulate the limitations of the leaf-level gas exchange model and the wind tunnel experiments. Regarding the model development, the premise is $U>0$ that guarantees a finite $g_{b, i}$ (i.e., $g_{t, \mathrm{CO}_{2}}$ and $g_{t, \mathrm{H}_{2} O}$ ). Without considering all the details of the biochemical signaling that govern movement of guard cells and mechanical constraints on this movement, the closure for $g_{s, \mathrm{CO}_{2}}$ is based on an assumption that stomates operate optimally to maximize carbon gain per unit water loss. This assumption, while generally accepted and supported by a large corpus of data, need not hold when limitations other than water 
availability exists. Also, the calculations for $g_{b, i}$ rely on empirical formations and an effective leaf dimension (i.e., $d$ ) that needs further elaboration to account for detailed aerodynamic modifications surrounding leaf bodies due to wind contact angle, leaf orientation and micro-roughness of the leaf surface. The energy balance assumes leaves have no thermal inertia and that surface temperature adjusts instantly to changes in wind speed. For some species, this assumption appears to be fair (Katul et al., 1998) though leaf thermal properties and leaf volume must be factored in. Last, the calculations here ignore the mesophyll conductance that may become limiting under increased soil moisture stress conditions.

Direct comparisons between modeled and measured $f_{e}$ in the wind tunnel was not possible as well. The lack of measured physiological parameters and the absence of total leaf area needed to convert sapflow velocity to transpiration rate for the potted plants was the main cause for the absence of such one-to-one comparison. Another major limitation of the wind tunnel experiment is the lack of high PPFD conditions, especially at PPFD values where the $f_{e}$-U reversed its monotonically increasing trend. Notwithstanding all the aforementioned issues, the overall trends in actual $f_{e}$ with respect to $U$ are reflected in measured steady-state $V_{s}$ through the normalization when all other conditions (i.e., PPFD, $A_{l}, A_{s}$ and soil water status) are maintained nearly constant throughout each experiment.

\section{Conclusion}

The primary goal here was to explain the conditions leading to $\partial f_{e} / \partial U>0$ or $<0$ with increasing $U$. To address this goal, the sign of $\partial f_{e} / \partial U$ was mainly discussed with the aid of a gas transfer model that explicitly accounts for boundary layer conductance, evaporative cooling, and soil moisture stress across a wide range of wind speed conditions. The model combines the Farquhar photosynthesis model for atmospheric $\mathrm{CO}_{2}$ demand with stomatal optimization theories to infer $f_{e}$. Consistent with model prediction, a positive sign of $\partial f_{e} / \partial U$ at low PPFD regime was shown by published and newly reported sap flow measurements conducted in a wind tunnel for two species (i.e., Pachira macrocarpa and Messerschmidia argentea) across a wide range of wind speed and two different soil water availability. Based on model results for a broad range of environmental conditions and wind tunnel measurements for a restricted range of environmental conditions, a number of conclusions can be drawn:

(1) Leaf-level transpiration monotonically increases with increasing mean wind speed when PPFD is low. This finding is supported by both sap flow measurements in the wind-tunnel and model calculations. However, the model calculations also suggest a possible $\partial f_{e} / \partial U<0$ at high PPDF levels. This transition from $\partial f_{e} / \partial U>0$ to $\partial f_{e} / \partial U<0$ occurs when the Bowen ratio is $\geq 0.75$. To be specific, surface cooling (i.e., $H<0$ ) at low light regime guarantees a $\partial f_{e} / \partial U>0$ for all $U$. At high light levels, $\partial f_{e} / \partial U<0$ can occur due to surface heating (i.e., $H>0$ ) that suppresses $f_{e}$ because of rapid increases in $H$ with increasing $U$ if net radiation at the leaf surface remains roughly the same.

(2) When soil water availability is limited, the transition PPFD value reflecting the reversed sign of $\partial f_{e} / \partial U$ tends to be lower. This can be explained by reduction in $f_{e}$ (i.e., evaporative cooling) that enhances $H$ (i.e., surface heating) and Bowen ratio leading to a transition at a lower light regime. On the other hand, $\partial f_{e} / \partial U<0$ may not be realized for common environmental conditions when atmospheric evaporative demand is large under well-watered soil condition. Given this specific condition, evaporative cooling dominates and $\partial f_{e} / \partial U>0$ prevails for all PPFD. 
(3) Modeled stomatal conductance to $\mathrm{CO}_{2}$ (i.e., $g_{s, \mathrm{CO}_{2}}$ ) can be impacted positively or negatively by aerodynamic modifications based on $U$, especially when the leaf is 'decoupled' from the atmosphere. The assimilation and transpiration rates as well as the ratio of the inter-cellular to ambient atmospheric $\mathrm{CO}_{2}$ concentration and WUE are also altered by wind speed conditions . The degree of alteration depends on environmental factors (e.g., light availability, water availability in the soil and evaporative demand) imposed upon the plant system. Unlike models that assume well-coupled conditions, the proposed modeling approach is capable of capturing theses non-monotonic behaviors with respect to $U$. Thus, it may be used to improve the predictability of canopy-level $\mathrm{CO}_{2}$ and $\mathrm{H}_{2} \mathrm{O}$ fluxes reflecting whole-plant responses to the environment. As $U$ and PPFD can be highly variable within vegetated canopies, the model up-scaling process from leaf to canopy level requires appropriate coupling to the light attenuation and flow field (e.g., Launiainen et al. (2011)) given information on leaf area density and leaf nitrogen content distributions.

Current uncertainties in modeling leaf-level gas exchange for $\mathrm{CO}_{2}$ and water vapor can be reduced when the interplay between the micro-environment (i.e., flow and temperature fields) and leaf attributes (e.g., $d$ ) are appropriately described without implementing empirical formulations to determine the boundary layer conductances. Moreover, the model calculations are only valid for finite $U$. Given that finite $U$ throughout vegetated medium is not uncommon in many ecosystems (Katul et al., 2004) suggests that this limitation may not be too restrictive for natural settings. Future studies on the measurements of $g_{s, \mathrm{CO}_{2}}, f_{e}$ and $f_{c}$ within the laminar boundary layer when leaves experience natural $U$ are needed to evaluate the proposed model predictive ability. Also, additional laboratory and field experiments for different species are required to differentiate wind effects on transpiration rate at the leaf scale from canopy scales, especially when the vertical distributions of leaf orientation, radiative forcing and wind speed within tall canopies are statistically non-uniform. 


\section{ACKNOWLEDGMENTS}

567 Support from the National Science Foundation (NSF-CBET-103347 and NSF-EAR-1344703), ${ }_{568}$ the U.S. Department of Energy (DOE) through the Office of Biological and Environmen${ }_{569}$ tal Research (BER) Terrestrial Carbon Processes (TCP) program (DE-SC0006967 and DE570 SC0011461), and the Swedish Research Council FORMAS through a project: Nitrogen and 571 Carbon in Forests is acknowledged. 
1

2

3

4

7

8

9

10

11

12

13

14

15

16

17

18

19

20

21

22

23

24

25

26

27

28

29

30

31

32

33

34

35

36

37

38

39

40

41

42

43

44

45

46

47

48

49

50

51

52

53

54

55

56

57

58

59

60

61

62

63

64

65

\section{$572 \quad$ List of Tables}

1. Physiological parameters and their temperature adjustments for biochemical model (Campbell and Norman, 1998) 
Table 1: Physiological parameters and their temperature adjustments for biochemical model (Campbell and Norman, 1998)

\begin{tabular}{lll}
\hline Parameters & Value or temperature adjustment & Unit \\
\hline$V_{c \max , 25^{\mathrm{a}}}{ }^{\mathrm{a}}$ & 50 & $\mu \mathrm{mol} \mathrm{m}^{-2} \mathrm{~s}^{-1}$ \\
$J_{\max , 25}{ }^{\mathrm{a}}$ & 100 & $\mu \mathrm{mol} \mathrm{m}^{-2} \mathrm{~s}^{-1}$ \\
$K_{c, 25}$ & 300 & $\mu \mathrm{mol} \mathrm{mol}^{-1}$ \\
$K_{o, 25}$ & 300 & $\mathrm{mmol} \mathrm{mol}^{-1}$ \\
$C_{o a}$ & $210 \quad \exp \left[0.088\left(T_{s}-25\right)\right]$ & $\mathrm{mmol} \mathrm{mol}{ }^{-1}$ \\
$V_{c, \text { max }}$ & $V_{c \max , 25} \frac{\mu \mathrm{mol} \mathrm{m} \mathrm{s}^{-1}}{1+\exp \left[0.29\left(T_{s}-41\right)\right]}$ & \\
$J_{\text {max }}{ }^{\mathrm{b}}$ & $J_{\max , 25} \exp \left[\frac{160\left(T_{s}-25\right)}{298 R T_{s}}\right]$ & $\mu \mathrm{mol} \mathrm{m}^{-2} \mathrm{~s}^{-1}$ \\
$K_{c}$ & $K_{c, 25} \exp \left[0.074\left(T_{s}-25\right)\right]$ & $\mu \mathrm{mol} \mathrm{mol}^{-1}$ \\
$K_{o}$ & $K_{o, 25} \exp \left[0.018\left(T_{s}-25\right)\right]$ & $\mathrm{mmol} \mathrm{mol}^{-1}$ \\
$\tau$ & $2.6 \exp \left[-0.056\left(T_{s}-25\right)\right]$ & $\mathrm{mmol} \mathrm{mol}^{-1}$ \\
$\Gamma^{*}$ & $\frac{C_{o a}}{2 \tau}$ & $\mu \mathrm{mol} \mathrm{mol}^{-1}$ \\
\hline
\end{tabular}

a The values of $V_{\text {cmax }, 25}$ and $J_{\max , 25}$ were taken to be within the range of the data reported elsewhere (Wang et al., 1996; Wullschleger, 1993).

b The formulations of $J_{\max }$ and $V_{c, \max }$ dependent on the normalized $J_{\max , 25}$ and $V_{c \max , 25}$ at $25^{\circ} \mathrm{C}$ were adopted from elsewhere (Campbell and Norman, 1998; Bernacchi et al., 2001; Medlyn et al., 2002). 


\section{List of Figures}

1. Schematic of the mass $\left(\mathrm{CO}_{2}\right.$ and water vapor) and energy transfer between the leaf and the atmosphere. Note that $u$ is the average wind velocity at the distance $y$ from leaf surface within the laminar boundary layer and $y_{b}$ is the thickness of the laminar boundary layer.

2. (a) Flowchart of numerical calculation process for the model system.

3. Modeled transpiration rate $\left(f_{e}\right)$, assimilation rate $\left(f_{c}\right)$, stomatal conductance $\left(g_{s, \mathrm{CO}_{2}}\right)$, Bowen ratio $(H / L E)$, WUE $\left(f_{c} / f_{e}\right)$ and the ratio of the inter-cellular to leaf-surface $\mathrm{CO}_{2}$ concentration $\left(c_{i} / c_{s}\right)$ as a function of wind speed $(U)$ and photosynthetically active radiation (PPFD) for well-watered soil condition $\left(\lambda=0.001 \mu \mathrm{mol} \mathrm{mol}^{-1} \mathrm{kPa}^{-1}\right)$ and small evaporative demand $(R H=60 \%)$. Note that the transition PPFD for the reversal sign of $\partial f_{e} / \partial U$ and $\partial f_{c} / \partial U$ are 1550 and $1250 \mu \mathrm{mol} \mathrm{m}^{-2} \mathrm{~s}^{-1}$ and represented by the broken lines, respectively. The broken line for Bowen ratio $(\approx 0.75)$ represents the corresponding transition for $f_{e}$.

4. Same as Figure 3 but for water-stressed soil conditions $\left(\lambda=5 \mu \mathrm{mol} \mathrm{mol}{ }^{-1} \mathrm{kPa}^{-1}\right)$ and small evaporative demand $(R H=60 \%)$. Note that the transition PPFD for the reversal sign of $\partial f_{e} / \partial U$ and $\partial f_{c} / \partial U$ are 1350 and $1150 \mu \mathrm{mol} \mathrm{m}^{-2} \mathrm{~s}^{-1}$ and represented by the broken lines, respectively. The broken line for Bowen ratio $(\approx 0.75)$ represents the corresponding transition for $f_{e}$.

5. Same as Figure 3 but for well-watered soil condition $\left(\lambda=0.001 \mu \mathrm{mol} \mathrm{mol}^{-1} \mathrm{kPa}^{-1}\right)$ and high evaporative demand $(R H=20 \%)$.

6. Same as Figure 3 but for water-stressed soil conditions $\left(\lambda=5 \mu \mathrm{mol} \mathrm{mol}^{-1} \mathrm{kPa}^{-1}\right)$ and high evaporative demand $(R H=20 \%)$. Note that the transition PPFD for the reversal sign of $\partial f_{e} / \partial U$ and $\partial f_{c} / \partial U$ are 1400 and $1250 \mu \mathrm{mol} \mathrm{m} \mathrm{m}^{-2} \mathrm{~s}^{-1}$ and represented by the broken lines, respectively. The broken line for Bowen ratio $(\approx 0.75)$ represents the corresponding transition for $f_{e}$.

7. The $f_{e}-U$ trends under two selected light conditions (i.e., PPFD=600 and $1600 \mu \mathrm{mol} \mathrm{m}^{-2}$ $\mathrm{s}^{-1}$ ) for the four scenarios. Note that the model results here are extracted from Figure 3, 4, 5 and 6 to illustrate the persistent monotonic increases in $f_{e}$ under low light condition but possible non-monotonic variations or decreasing trends in $f_{e}$ at the high light level.

8. (a) A photograph of the two broadleaf species and (b) the wind-tunnel and (c) schematic of the wind-tunnel setup.

9. (a) Comparisons between measured (symbols) and modeled (solid line) nocturnal $f_{e}$ normalized by its maximum nocturnal value for different wind speed conditions $(U)$. (b) Same as figure 9(a) but for daytime normalized- $f_{e}$, where the normalization is based on maximum daytime value. (c) Modeled stomatal conductance $\left(g_{s, \mathrm{CO}_{2}}\right)$ under different wind conditions. The data is taken from Chu et al. (2009). Note that the best-fit nocturnal residual conductance $\left(g_{\text {res }} \approx 0.04 \mathrm{~mol} \mathrm{~m} \mathrm{~m}^{-2} \mathrm{~s}^{-1}\right.$ ) is first obtained from matching nocturnal $f_{e}$ computed through energy balance to the measured nocturnal $f_{e}$ as shown in figure 9(a), and the optimality hypothesis is implemented to compute daytime $f_{e}$ and $g_{s, \mathrm{CO}_{2}}$ as shown in figures 9(b) and $9(\mathrm{c})$.

10. Comparison between measured and modeled normalized- $f_{e}$ during daytime for Pachira macrocarpa $(\mathrm{Pm})$ and Messerschmidia argentea $(\mathrm{Ma})$ for different soil water conditions and across a wide range of wind speeds. The solid line represents 1:1 line. The coefficient of determination $R^{2}=0.85(p<0.01)$. Note that WW and WS respectively refer to wellwatered and water-stressed condition. The direction of increasing $U$ is also indicated by the arrow suggesting $\partial f_{e} / \partial U>0$ for all data set at low PPFD. 


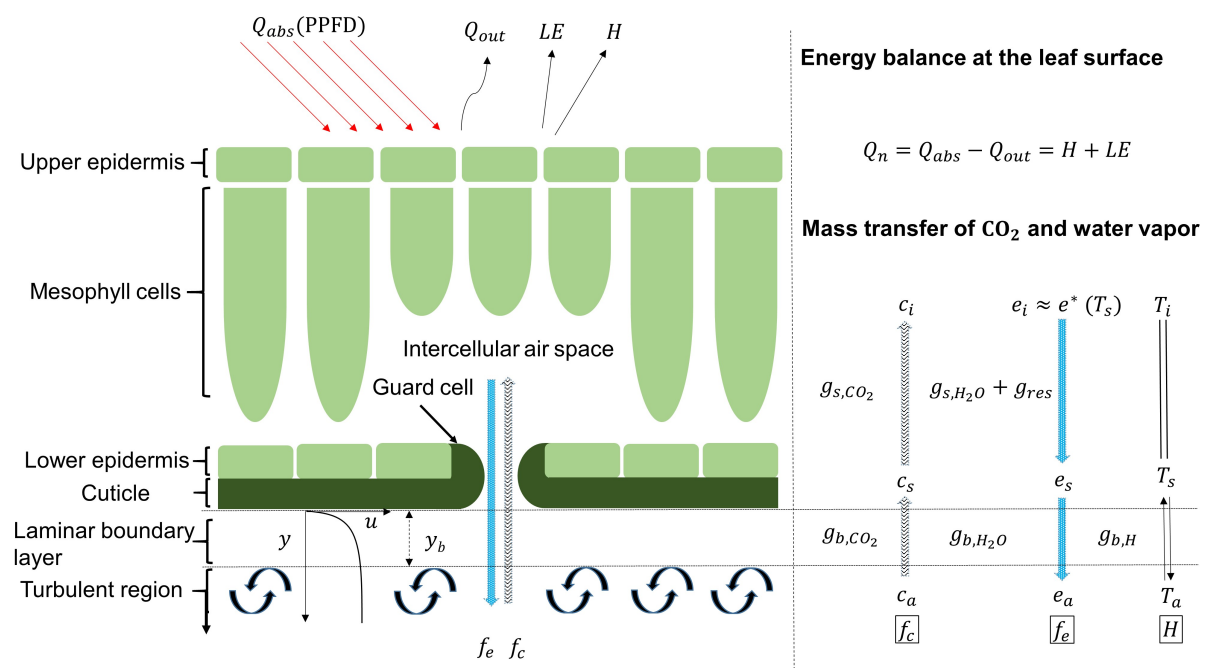

Figure 1: Schematic of the mass $\left(\mathrm{CO}_{2}\right.$ and water vapor) and energy transfer between the leaf and the atmosphere. Note that $u$ is the average wind velocity at the distance $y$ from leaf surface within the laminar boundary layer and $y_{b}$ is the thickness of the laminar boundary layer. 


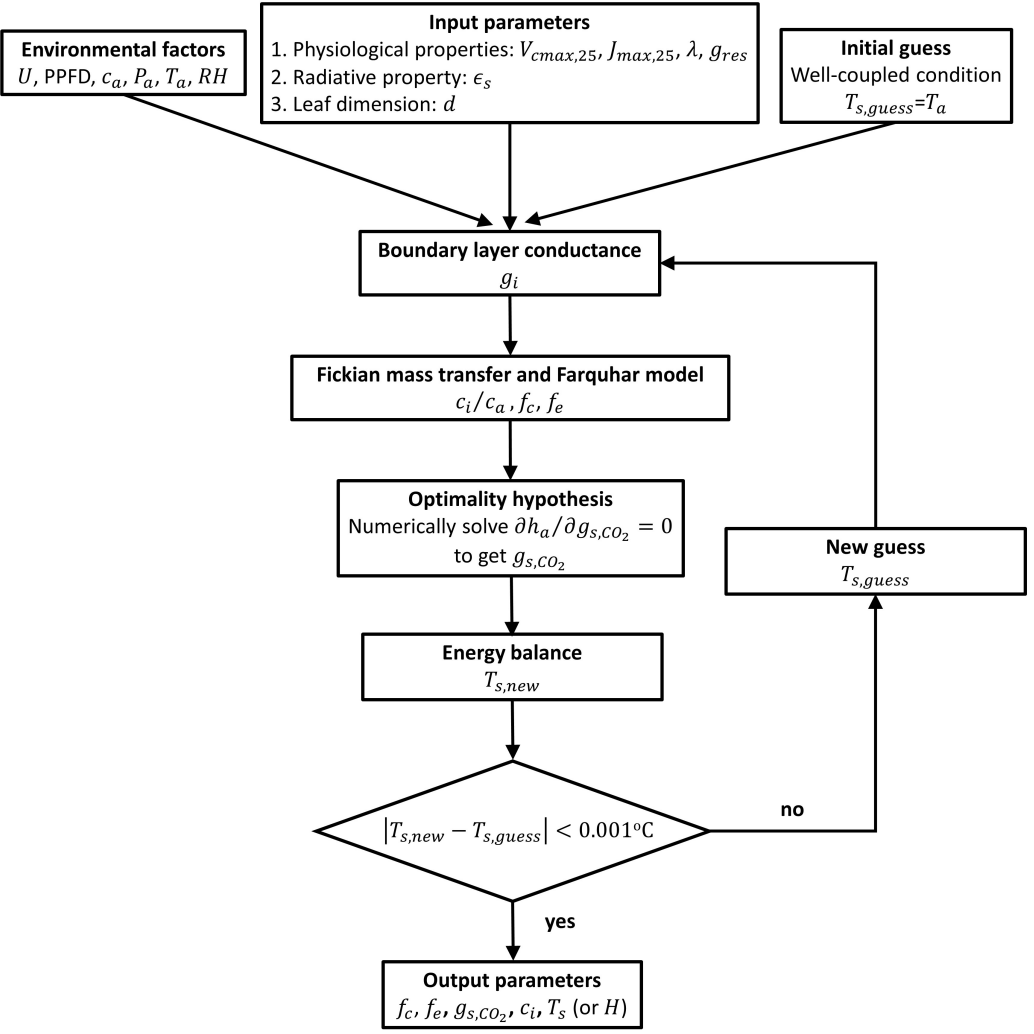

Figure 2: Flowchart of numerical calculation process for the model system. 

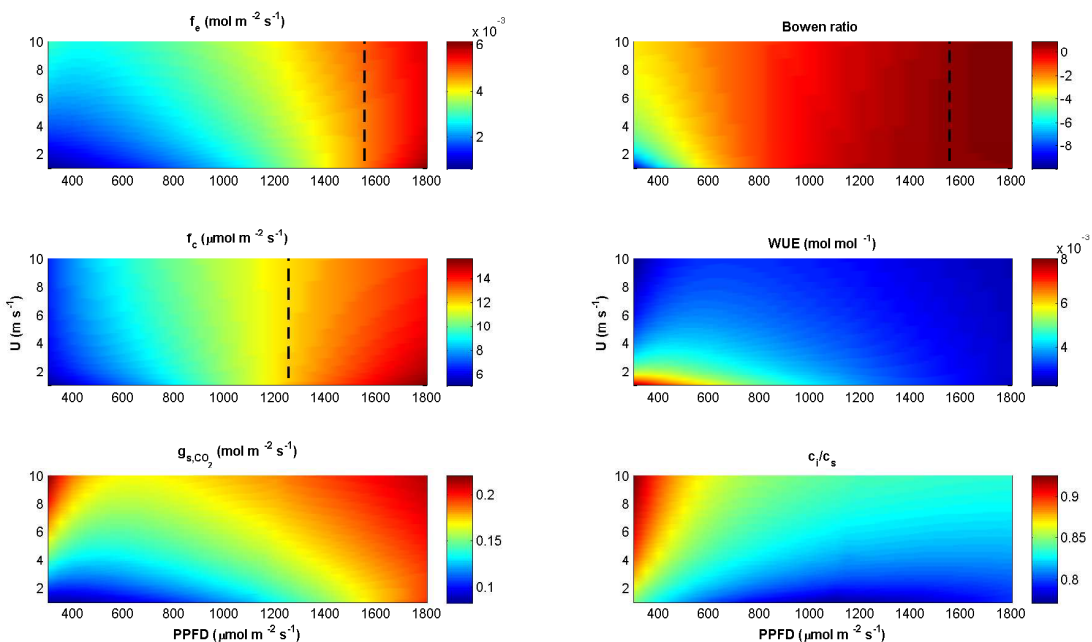

Figure 3: Modeled transpiration rate $\left(f_{e}\right)$, assimilation rate $\left(f_{c}\right)$, stomatal conductance $\left(g_{s, C O_{2}}\right)$, Bowen ratio $(H / L E)$, WUE $\left(f_{c} / f_{e}\right)$ and the ratio of the inter-cellular to leaf-surface $\mathrm{CO}_{2}$ concentration $\left(c_{i} / c_{s}\right)$ as a function of wind speed $(U)$ and photosynthetically active radiation (PPFD) for well-watered soil condition $\left(\lambda=0.001 \mu \mathrm{mol} \mathrm{mol}^{-1} \mathrm{kPa}^{-1}\right)$ and small evaporative demand $(R H=60 \%)$. Note that the transition PPFD for the reversal sign of $\partial f_{e} / \partial U$ and $\partial f_{c} / \partial U$ are 1550 and $1250 \mu \mathrm{mol} \mathrm{m}^{-2} \mathrm{~s}^{-1}$ and represented by the broken lines, respectively. The broken line for Bowen ratio $(\approx 0.75)$ represents the corresponding transition for $f_{e}$. 

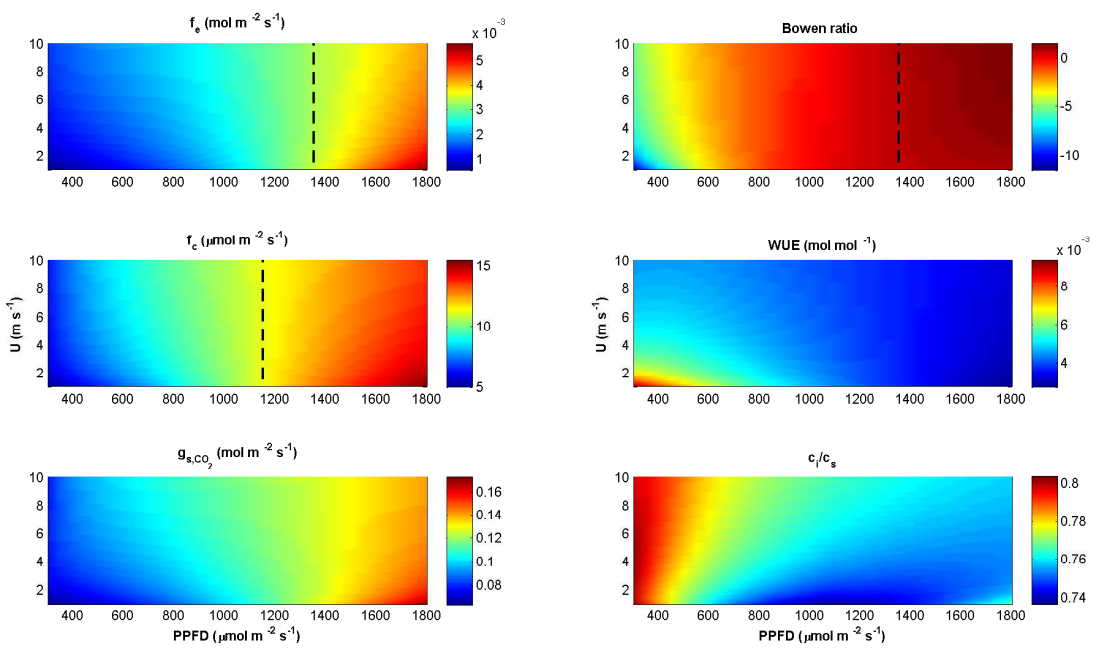

Figure 4: Same as Figure 3 but for water-stressed soil conditions $\left(\lambda=5 \mu \mathrm{mol} \mathrm{mol}^{-1} \mathrm{kPa}^{-1}\right)$ and small evaporative demand $(R H=60 \%)$. Note that the transition PPFD for the reversal sign of $\partial f_{e} / \partial U$ and $\partial f_{c} / \partial U$ are 1350 and 1150 $\mu \mathrm{mol} \mathrm{m} \mathrm{m}^{-2} \mathrm{~s}^{-1}$ and represented by the broken lines, respectively. The broken line for Bowen ratio $(\approx 0.75)$ represents the corresponding transition for $f_{e}$. 

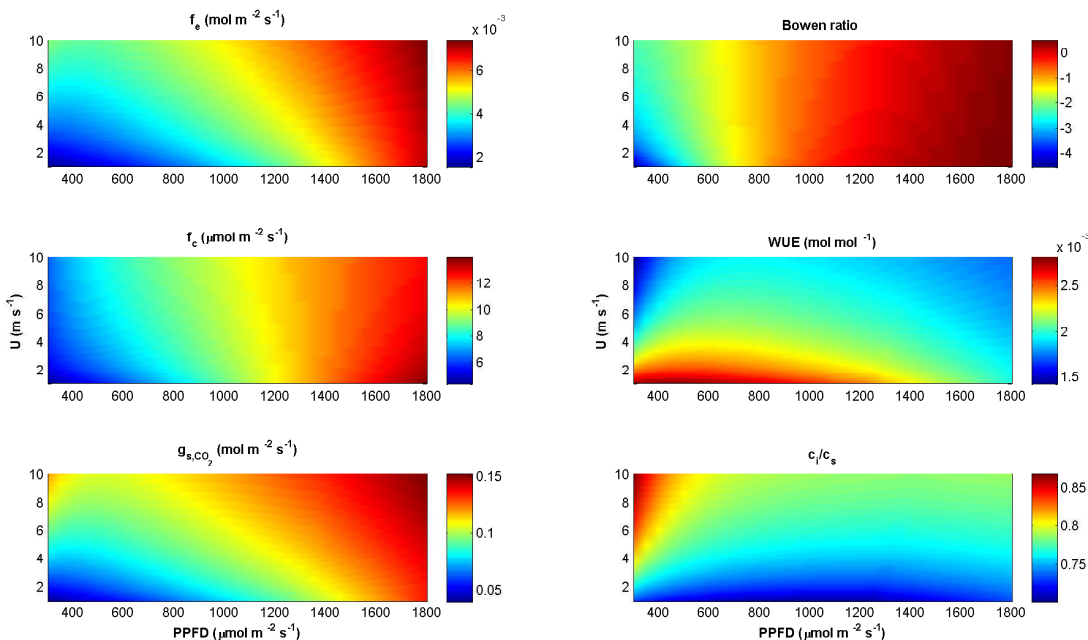

Figure 5: Same as Figure 3 but for well-watered soil condition $\left(\lambda=0.001 \mu \mathrm{mol} \mathrm{mol}^{-1} \mathrm{kPa}^{-1}\right)$ and high evaporative demand $(R H=20 \%)$. 

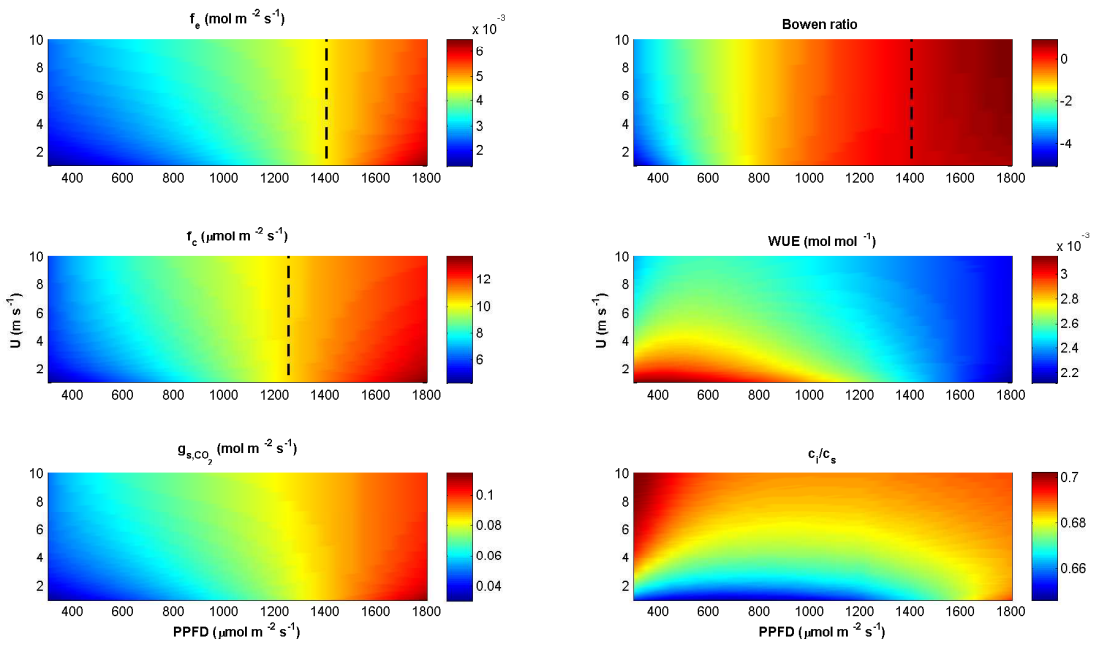

Figure 6: Same as Figure 3 but for water-stressed soil conditions $\left(\lambda=5 \mu \mathrm{mol} \mathrm{mol}^{-1} \mathrm{kPa}^{-1}\right)$ and high evaporative demand $(R H=20 \%)$. Note that the transition PPFD for the reversal sign of $\partial f_{e} / \partial U$ and $\partial f_{c} / \partial U$ are 1400 and 1250 $\mu \mathrm{mol} \mathrm{m} \mathrm{m}^{-2} \mathrm{~s}^{-1}$ and represented by the broken lines, respectively. The broken line for Bowen ratio $(\approx 0.75)$ represents the corresponding transition for $f_{e}$. 

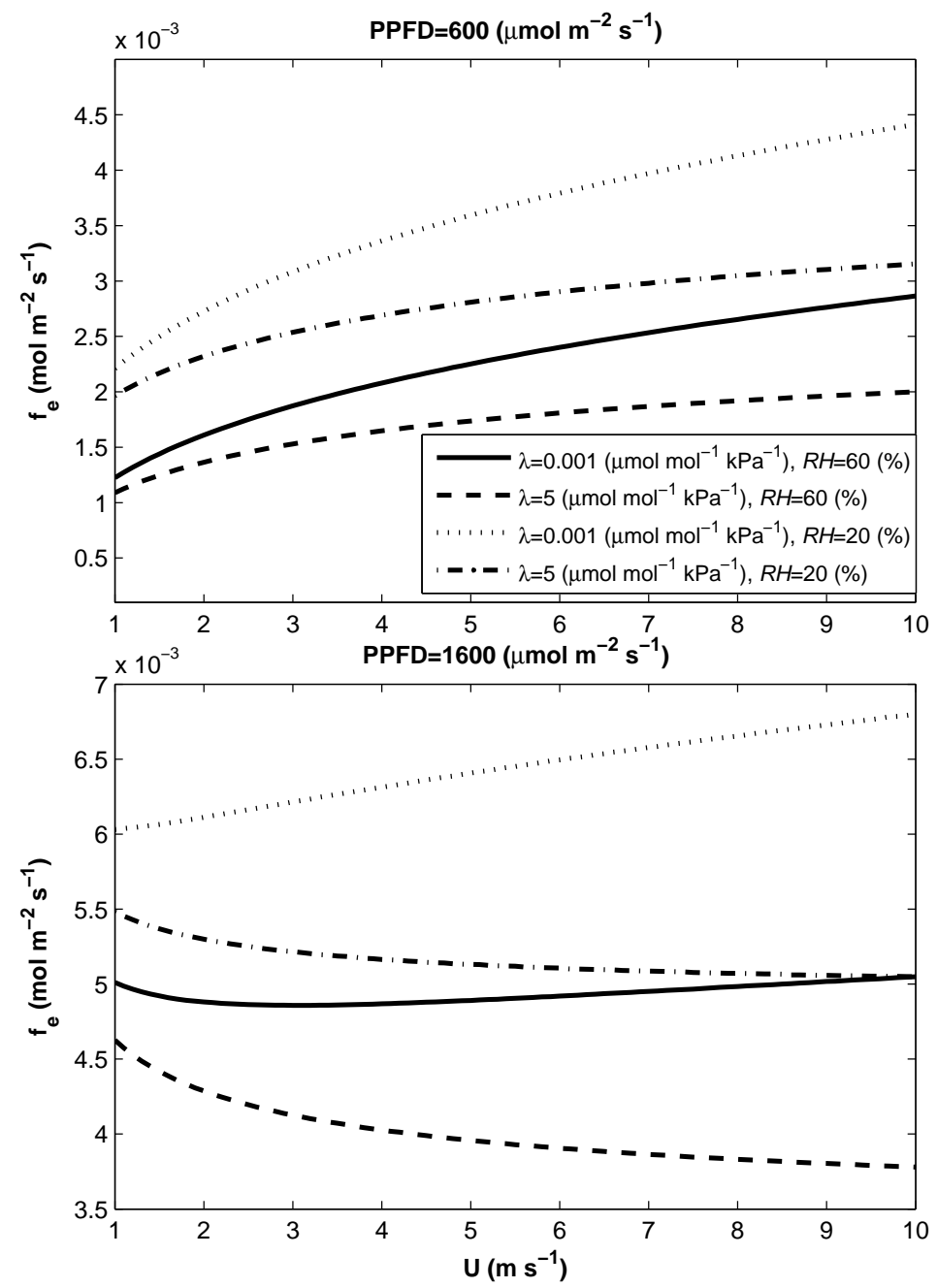

Figure 7: The $f_{e}-U$ trends under two selected light conditions (i.e., PPFD=600 and $1600 \mu \mathrm{mol} \mathrm{m}^{-2} \mathrm{~s}^{-1}$ ) for the four scenarios. Note that the model results here are extracted from Figure 3, 4, 5 and 6 to illustrate the persistent monotonic increases in $f_{e}$ under low light condition but possible non-monotonic variations or decreasing trends in $f_{e}$ at the high light level. 


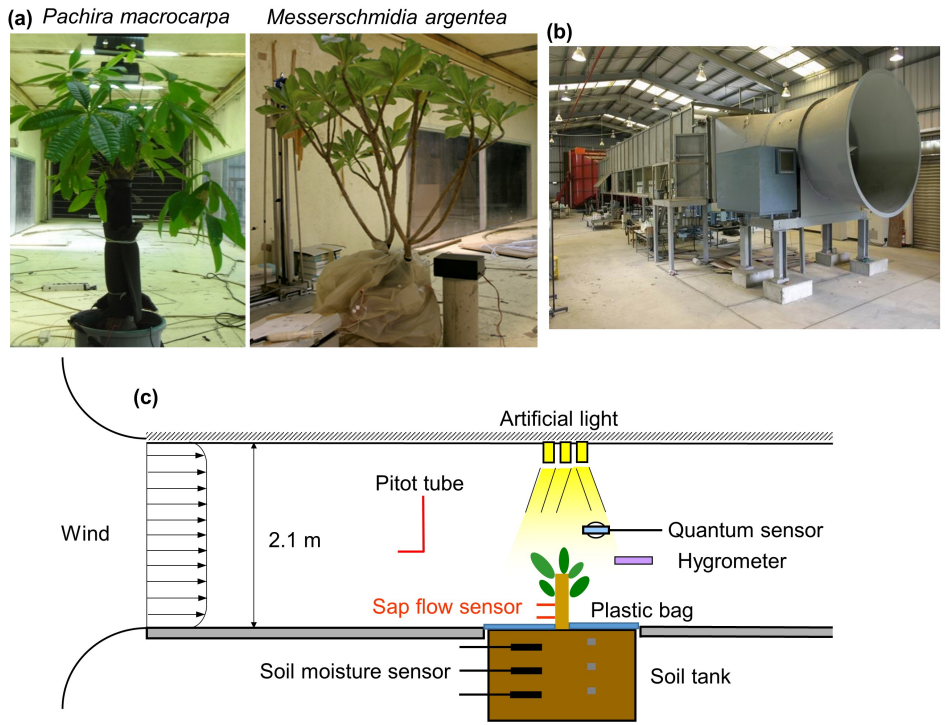

Figure 8: (a) A photograph of the two broadleaf species and (b) the wind-tunnel and (c) schematic of the wind-tunnel setup. 

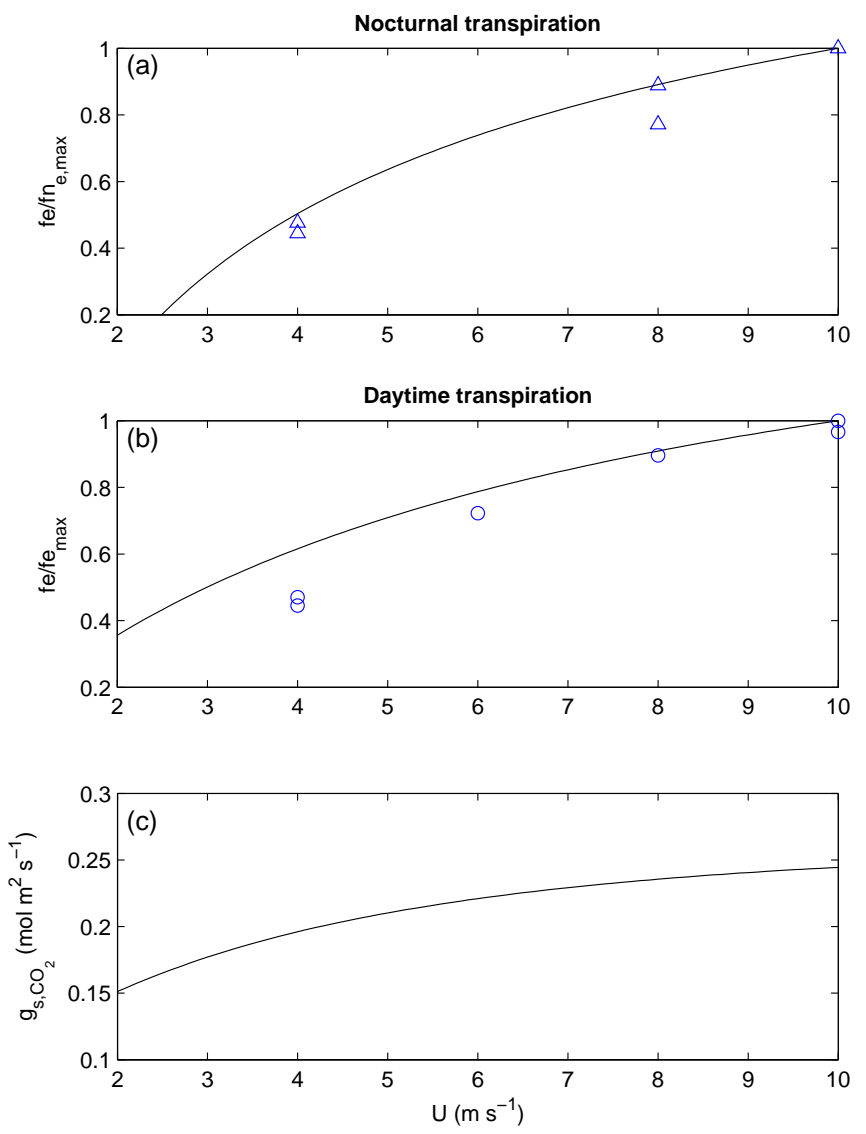

Figure 9: (a) Comparisons between measured (symbols) and modeled (solid line) nocturnal $f_{e}$ normalized by its maximum nocturnal value for different wind speed conditions $(U)$. (b) Same as figure 9(a) but for daytime normalized- $f_{e}$, where the normalization is based on maximum daytime value. (c) Modeled stomatal conductance $\left(g_{s, \mathrm{CO}_{2}}\right)$ under different wind conditions. The data is taken from Chu et al. (2009). Note that the best-fit nocturnal residual conductance $\left(g_{\text {res }} \approx 0.04 \mathrm{~mol} \mathrm{~m}^{-2} \mathrm{~s}^{-1}\right)$ is first obtained from matching nocturnal $f_{e}$ computed through energy balance to the measured nocturnal $f_{e}$ as shown in figure 9 (a), and the optimality hypothesis is implemented to compute daytime $f_{e}$ and $g_{s, \mathrm{CO}_{2}}$ as shown in figures $9(\mathrm{~b})$ and $9(\mathrm{c})$. 


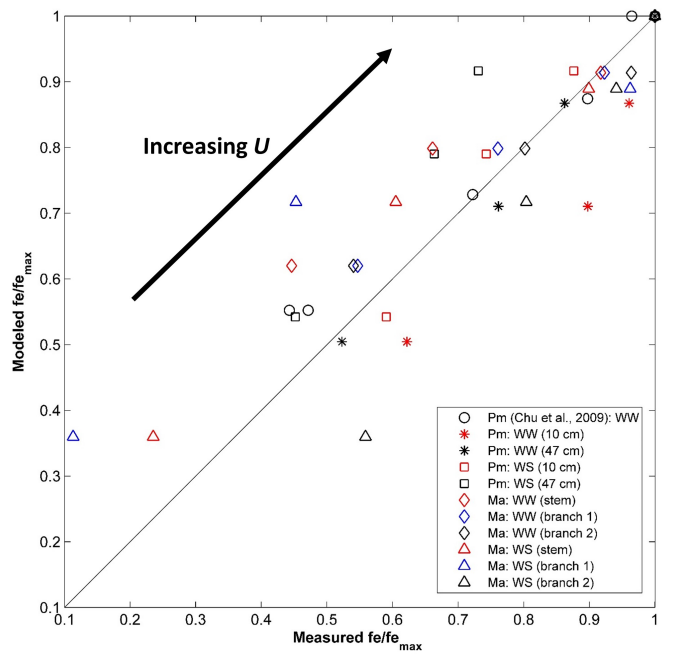

Figure 10: Comparison between measured and modeled normalized- $f_{e}$ during daytime for Pachira macrocarpa $(\mathrm{Pm})$ and Messerschmidia argentea $(\mathrm{Ma})$ for different soil water conditions and across a wide range of wind speeds. The solid line represents 1:1 line. The coefficient of determination $R^{2}=0.85(p<0.01)$. Note that WW and WS respectively refer to well-watered and water-stressed condition. The direction of increasing $U$ is also indicated by the arrow suggesting $\partial f_{e} / \partial U>0$ for all data set at low PPFD. 


\section{Appendix A. Experiment}

The effects of variable $U$ on $f_{e}$ were explored using sap flow measurements for two potted broadleaf species (i.e., Pachira macrocarpa and Messerschmidia argentea) placed in a large wind-tunnel (see Figure 8). The working section of the wind tunnel is $18.5 \mathrm{~m}$ long, $2.1 \mathrm{~m}$ tall and $3.0 \mathrm{~m}$ wide as described in Chu et al. (2009). Sap flow measurements were conducted across a wide range of $U$ (up to $\left.8 \mathrm{~m} \mathrm{~s}^{-1}\right)$ at a fixed PPFD $\left(=250 \mu \mathrm{mol} \mathrm{m}^{-2} \mathrm{~s}^{-1}\right.$ for all runs) or zero PPFD (plants covered). The soil type in the pot was sandy loam with a permanent wilting point (on a volume basis) of $\theta_{w}=5.6 \%$. Two scenarios were explored for soil water availability: (1) wellwatered and (2) water-stressed conditions. For well-watered conditions, the soil was watered with plethoric water and drainage through a small hole at the bottom of the pot proceeded for three hours prior to each experiment. For water-stressed conditions, the pot was not watered for 12 days and volumetric soil moisture $\theta$ measured by a soil moisture sensor (EC10, Decagon Inc.) positioned at $5.0 \mathrm{~cm}$ underneath the soil surface dropped from $\theta=35.8 \%$ for near saturated conditions to $\theta=27.7 \%$ and $\theta=24.0 \%$ for Pachira macrocarpa and Messerschmidia argentea, respectively.

In this open-circuit suction-type wind-tunnel, the plant pot was placed in a soil tank covered with plastic bag to prevent soil evaporation in the test section. For both well-watered and waterstressed soil condition, $U=2,4,6$ and $8 \mathrm{~m} \mathrm{~s}^{-1}$ in the test section were produced by a fan and monitored by a pitot tube. Granier-type (Granier, 1987) heat dissipation sensors were employed for measuring sap flow and their calibration as well as installation details are described in Chu et al. (2009). During the course of each experiment, any potential cooling effect induced by increasing $U$ were minimized by covering the sensors with Styrofoam. Sap flow velocities $\left(V_{s}\right)$ were measured simultaneously at two different locations (i.e., $10 \mathrm{~cm}$ and $37 \mathrm{~cm}$ from the soil surface) along the main stem for Pachira macrocarpa. The $V_{s}$ was measured in the main stem and two branches for Messerschmidia argentea. The stem and branch characteristics for each species are presented in Table Appendix A.1. Steady-state $U$ can be achieved approximately one to two minutes after the fan was turned on or when $U$ was altered. Following any abrupt alteration to $U$, a transient duration of 20 to 50 minutes is required for $V_{s}$ to reach a new steady state condition (Chu et al., 2009). The data reported here are all collected when $V_{s}$ attains steady state at each $U$. Environmental factors such as PPFD, $T_{a}$ and $R H$ were measured during the course of each experiment and remained nearly unaltered at the ambient indoor conditions. The $T_{a}$ and $R H$ were respectively measured to a resolution of $\pm 0.1{ }^{\circ} \mathrm{C}$ and $\pm 2 \%$ using a hygrotransmitter (HD9008TR, Delta Ohm Inc.). PPFD was nearly constant and controlled by multiple lamps and monitored by a quantum sensor (LI-190SZ, LI-COR Inc.). All instrument signals were recorded by a data logger (CR10X, Campbell Scientific Inc.) throughout each experiment. The average values of the environmental factors for these two species are summarized in Table Appendix 


\begin{tabular}{|c|c|c|}
\hline Species & Pachira macrocarpa & Messerschmidia argentea \\
\hline Total height $(\mathrm{cm})$ & 130 & 130 \\
\hline Main stem height $(\mathrm{cm})$ & 72 & 10 \\
\hline Main stem diameter $(\mathrm{cm})$ & 5.6 & 5.34 \\
\hline diameter $(\mathrm{cm})$ & - & 3.45 \\
\hline length $(\mathrm{cm})$ & - & 12 \\
\hline Branch 2 diameter $(\mathrm{cm})$ & - & 2.44 \\
\hline length $(\mathrm{cm})$ & - & 26 \\
\hline
\end{tabular}


Table Appendix A.2: Environmental factors and the marginal water use efficiency for the two species under two soil water conditions.

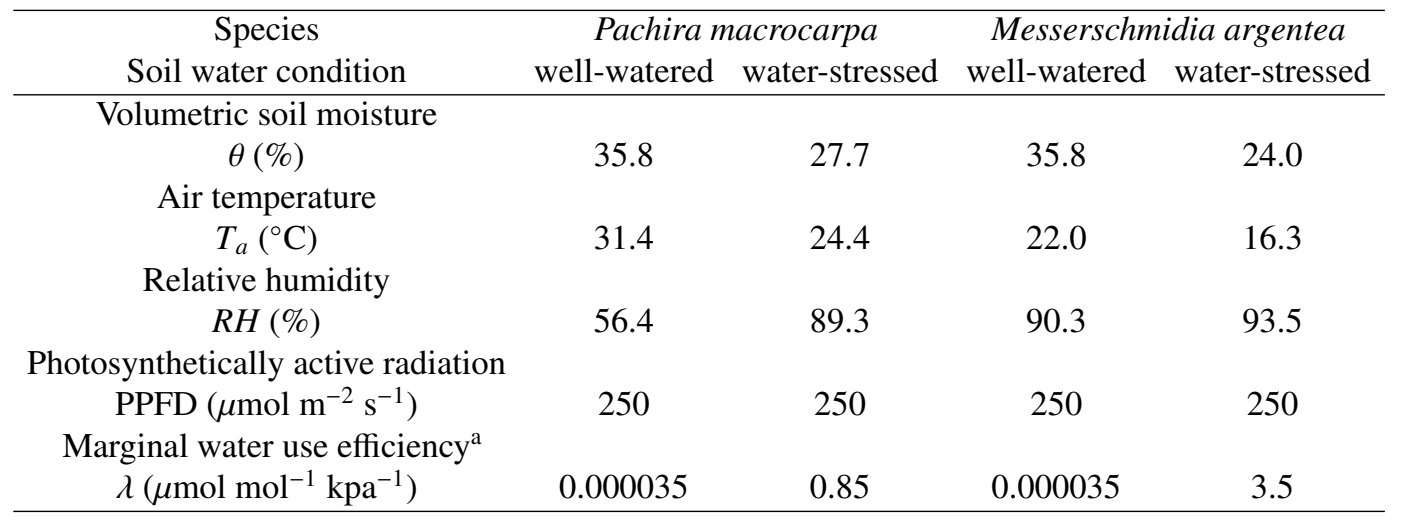

a The $\lambda$ values were assumed to be small and finite for well-watered soil condition (Katul et al., 2010), but larger for dryer soil (Katul et al., 2012; Mäkelä et al., 1996; Manzoni et al., 2011). 
1

2

3

4

7

8

9

10

11

12

13

14

15

16

17

18

19

20

21

22

23

24

25

26

27

28

29

30

31

32

33

34

35

36

37

38

39

40

41

42

43

44

45

46

47

48

49

50

51

52

53

54

55

56

57

58

59

60

61

62

63

64

65

\section{Appendix B. List of symbols}

658 All the symbols and units used throughout are summarized in Table Appendix B.1. 
Table Appendix B.1: Nomenclature

\begin{tabular}{|c|c|c|}
\hline Symbol & Description & Unit \\
\hline$A_{s}$ & Sapwood area & $\mathrm{m}^{2}$ \\
\hline$A_{l}$ & Total leaf area & $\mathrm{m}^{2}$ \\
\hline$C_{o a}$ & Ambient oxygen concentration & $\mathrm{mmol} \mathrm{mol}^{-1}$ \\
\hline$H$ & Sensible heat flux & $\mathrm{W} \mathrm{m} \mathrm{m}^{-2}$ \\
\hline$J$ & Electron transport rate & $\mu \mathrm{mol} \mathrm{m}^{-2} \mathrm{~s}^{-1}$ \\
\hline$J_{\max }$ & Light saturated rate of electron transport & $\mu \mathrm{mol} \mathrm{m} \mathrm{m}^{-2} \mathrm{~s}^{-1}$ \\
\hline$J_{\max , 25}$ & Normalized $J_{\max }$ at $25^{\circ} \mathrm{C}$ & $\mu \mathrm{mol} \mathrm{m}^{-2} \mathrm{~s}^{-1}$ \\
\hline$K_{c}$ & Michaelis constants for $\mathrm{CO}_{2}$ fixation & $\mu \mathrm{mol} \mathrm{mol}-1$ \\
\hline$K_{o}$ & Michaelis constants for oxygen inhibition & $\mathrm{mmol} \mathrm{mol}^{-1}$ \\
\hline$L$ & Latent heat of water vaporization & $\mathrm{J} \mathrm{mol}^{-1}$ \\
\hline$L E$ & Latent heat flux & $\mathrm{W} \mathrm{m}^{-2}$ \\
\hline PPFD & Photosynthetically active radiation & $\mu \mathrm{mol} \mathrm{m}^{-2} \mathrm{~s}^{-1}$ \\
\hline$P_{a}$ & Atmospheric pressure & $\mathrm{kPa}$ \\
\hline$Q_{n}$ & Net radiation & $\mathrm{W} \mathrm{m}^{-2}$ \\
\hline$Q_{a b s}$ & Absorbed radiation & $\mathrm{W} \mathrm{m^{-2 }}$ \\
\hline$Q_{\text {out }}$ & Emitted longwave radiation & $\mathrm{W} \mathrm{m}^{-2}$ \\
\hline$R_{d}$ & Daytime mitochondrial respiration rate & $\mu \mathrm{mol} \mathrm{m} \mathrm{m}^{-2} \mathrm{~s}^{-1}$ \\
\hline$R H$ & Relative humidity & $\%$ \\
\hline$T_{a}$ & Leaf surface temperature & ${ }^{\circ} \mathrm{C}$ \\
\hline$T_{i}^{a}$ & Intercellular temperature & ${ }^{\circ} \mathrm{C}$ \\
\hline$T_{s}$ & Ambient temperature & ${ }^{\circ} \mathrm{C}$ \\
\hline$U$ & Mean wind speed & $\mathrm{m} \mathrm{s}^{-1}$ \\
\hline VPD & Vapor pressure deficit & $\mathrm{kPa}$ \\
\hline$V_{c, \max }$ & Maximum carboxylation capacity under light-saturated conditions & $\mu \mathrm{mol} \mathrm{m} \mathrm{m}^{-2} \mathrm{~s}^{-1}$ \\
\hline$V_{\text {cmax }, 25}$ & Normalized $V_{c, \max }$ at $25^{\circ} \mathrm{C}$ & $\mu \mathrm{mol} \mathrm{m}^{-2} \mathrm{~s}^{-1}$ \\
\hline WUE & Water use efficiency & $\mathrm{mol} \mathrm{mol}^{-1}$ \\
\hline$c_{a}$ & Ambient $\mathrm{CO}_{2}$ concentration & $\mu \mathrm{mol} \mathrm{mol}-1$ \\
\hline$c_{i}$ & Intercellular $\mathrm{CO}_{2}$ concentration & $\mu \mathrm{mol} \mathrm{mol}-1$ \\
\hline$c_{p}$ & Capacity of dry air at constant pressure & $\mathrm{J} \mathrm{mol}^{-1} \mathrm{~K}^{-1}$ \\
\hline$d$ & Characteristic dimension of the leaf & $\mathrm{m}$ \\
\hline & Ambient water vapor pressure & $\mathrm{kPa}$ \\
\hline$e_{a}^{*}\left(T_{a}\right)$ & Saturated water vapor pressure at a given $T_{a}$ & $\mathrm{kPa}$ \\
\hline$e_{i}$ & Inter-cellular water vapor pressure & $\mathrm{kPa}$ \\
\hline$f_{c}$ & Assimilation rate & $\mu \mathrm{mol} \mathrm{m}{ }^{-2} \mathrm{~s}^{-1}$ \\
\hline$f_{e}$ & Transpiration rate & $\mathrm{mol} \mathrm{m}^{-2} \mathrm{~s}^{-1}$ \\
\hline$g_{b, C O_{2}}$ & Laminar boundary layer conductance for $\mathrm{CO}_{2}$ & $\mathrm{~mol} \mathrm{~m}^{-2} \mathrm{~s}^{-1}$ \\
\hline$g_{b, \mathrm{H}_{2} \mathrm{O}}$ & Laminar boundary layer conductance for water vapor & $\mathrm{mol} \mathrm{m}^{-2} \mathrm{~s}^{-1}$ \\
\hline$g_{b, H}$ & Laminar boundary layer conductance for heat & $\operatorname{mol~m}{ }^{-2} \mathrm{~s}^{-1}$ \\
\hline$g_{\text {cut }}$ & Cuticular conductance to water vapor & $\mathrm{mol} \mathrm{m}^{-2} \mathrm{~s}^{-1}$ \\
\hline$g_{\text {night }}$ & Nighttime stomatal conductance to water vapor & $\mathrm{mol} \mathrm{m}^{-2} \mathrm{~s}^{-1}$ \\
\hline$g_{\text {res }}$ & Nocturnal residual conductance & $\mathrm{mol} \mathrm{m}^{-2} \mathrm{~s}^{-1}$ \\
\hline$g_{s, \mathrm{CO}_{2}}$ & Stomatal conductance to $\mathrm{CO}_{2}$ & $\mathrm{~mol} \mathrm{~m}^{-2} \mathrm{~s}^{-1}$ \\
\hline$g_{s, H_{2} O}$ & Stomatal conductance to water vapor & $\mathrm{mol} \mathrm{m}^{-2} \mathrm{~s}^{-1}$ \\
\hline$g_{t, \mathrm{CO}_{2}}$ & Total conductance for $\mathrm{CO}_{2}$ & $\mathrm{~mol} \mathrm{~m}^{-2} \mathrm{~s}^{-1}$ \\
\hline$g_{t, \mathrm{H}_{2} \mathrm{O}}$ & Total conductance for water vapor & $\mathrm{mol} \mathrm{m}^{-2} \mathrm{~s}^{-1}$ \\
\hline$\Gamma^{*}$ & $\mathrm{CO}_{2}$ compensation point & $\mu \mathrm{mol} \mathrm{mol}{ }^{-1}$ \\
\hline$\epsilon_{S}$ & Leaf surface emissivity & Dimensionless \\
\hline$\sigma$ & Stefan-Boltzmann constant & $\mathrm{W} \mathrm{m^{-2 }} \mathrm{K}^{-4}$ \\
\hline$\lambda$ & Marginal water use efficiency & $\mu \mathrm{mol} \mathrm{mol}{ }^{-1} \mathrm{kPa}^{-1}$ \\
\hline$\theta$ & Volumetric soil moisture (on a volume basis) & $\%$ \\
\hline$\theta_{w}$ & Permanent wilting point (on a volume basis) & $\%$ \\
\hline
\end{tabular}




\section{Appendix C. leaf gas exchange model with well-coupled assumption}

When interpreting leaf gas exchange measurements in cuvettes, well-coupled condition between the leaf and atmosphere (i.e., $g_{b, i} \gg g_{s, i}$ ) is commonly assumed and the mass transfer of $\mathrm{CO}_{2}$ and water vapor adjacent to the leaf surface are given by:

$$
\begin{aligned}
& f_{c}=g_{s, \mathrm{CO}_{2}}\left(c_{a}-c_{i}\right) \\
& f_{e}=a g_{s, \mathrm{CO}_{2}} \mathrm{VPD},
\end{aligned}
$$

where $a=1.6$ is the relative diffusivity of water vapor with respect to $\mathrm{CO}_{2}$. Equation C. 1 also implies that $T_{s} \approx T_{a}, c_{s} \approx c_{a}$ and $e_{i}-e_{a} \approx \mathrm{VPD}$. Combining Equation C.1 and Equation 5, $c_{i}$ and $f_{c}$ can now be expressed as a function of $g_{s, \mathrm{CO}_{2}}$ instead of $g_{t, \mathrm{CO}_{2}}$ :

$$
\begin{aligned}
& \frac{c_{i}}{c_{a}}=\frac{1}{2}+\frac{1}{2 g_{s, C O_{2}} c_{a}}\left[-k_{1}-k_{2} g_{s, C O_{2}}+R_{d}\right. \\
& \left.+\sqrt{\left[k_{1}+\left(k_{2}-c_{a}\right) g_{s, C O_{2}}-R_{d}\right]^{2}-4 g_{s, C O_{2}}\left(-c_{a} g_{s, C O_{2}} k_{2}-k_{2} R_{d}-k_{1} \Gamma^{*}\right)}\right]
\end{aligned}
$$

and

$$
\begin{aligned}
& f_{c}=\frac{1}{2}\left[k_{1}+\left(k_{2}+c_{a}\right) g_{s, C O_{2}}+R_{d}\right. \\
& -\sqrt{\left[k_{1}+\left(k_{2}-c_{a}\right) g_{s, C O_{2}}-R_{d}\right]^{2}-4 g_{s, C O_{2}}\left(-c_{a} g_{s, C O_{2}} k_{2}-k_{2} R_{d}-k_{1} \Gamma^{*}\right)} .
\end{aligned}
$$

When optimality hypothesis (see Section 2.5) is again employed as a closure for $\mathrm{g}_{s, \mathrm{CO}_{2}}$, an analytical form of $\mathrm{g}_{s, \mathrm{CO}_{2}}$ can be derived:

$$
\begin{aligned}
& g_{s, C O_{2}}=\frac{-\left(c_{a}\left(k_{1}-R_{d}\right)-k_{2}\left(k_{1}+R_{d}\right)-2 k_{1} \Gamma^{*}\right)(a \mathrm{VPD} \lambda)}{\left(c_{a}+k_{2}\right)^{2}\left(c_{a}+k_{2}-a \mathrm{VPD} \lambda\right)} \\
& +\frac{\sqrt{a \mathrm{VPD} \lambda k_{1}\left(k_{2}+\Gamma^{*}\right)\left(k_{2} R_{d}+c a\left(-k_{1}+R_{d}\right)+k_{1} \Gamma^{*}\right)\left(c_{a}+k_{2}-2 a \mathrm{VPD} \lambda\right)^{2}\left(-c_{a}-k_{2}+a \mathrm{VPD} \lambda\right)}}{a \operatorname{VPD} \lambda\left(c_{a}+k_{2}\right)^{2}\left(c_{a}+k_{2}-a \mathrm{VPD} \lambda\right)} .
\end{aligned}
$$

It is evident that the predicted $g_{s, \mathrm{CO}_{2}}$ is not impacted by $U$ at a given PPFD when the wellcoupled approximation is adopted. However, previous models often combine this representation of $g_{s, \mathrm{CO}_{2}}$ with boundary layer conductance to accommodate wind effects on $f_{e}$ and $f_{c}$, leading to monotonic increases in $f_{e}$ and $f_{c}$ with increasing $U$. To contrast, the modeled $f_{e}, f_{c}$ and $g_{s, \mathrm{CO}_{2}}$ with respect to variable $U$ and PPFD for well-watered soil condition $(\lambda=0.001 \mu \mathrm{mol}$ $\left.\mathrm{mol}^{-1} \mathrm{kPa}^{-1}\right)$ and small evaporative demand $(R H=60 \%)$ (same conditions as Section 3.1.1) are shown in Figure Appendix C.1. The predicted $f_{e}$ and $f_{c}$ can deviate from the modeled results without invoking the well-coupled approximation (see Figure 3) by up to $60 \%$ and $17 \%$ at high wind speed conditions, which is not trivial. 

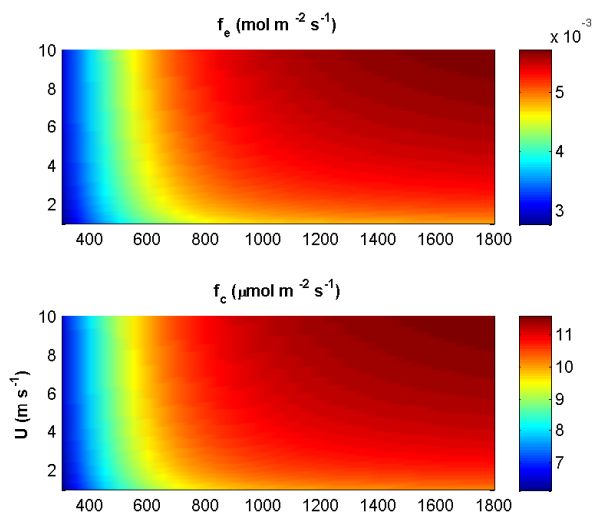

$\mathrm{g}_{\mathrm{s}, \mathrm{Co}}\left(\mathrm{mol} \mathrm{m} \mathrm{m}^{-2} \mathrm{~s}^{-1}\right)$

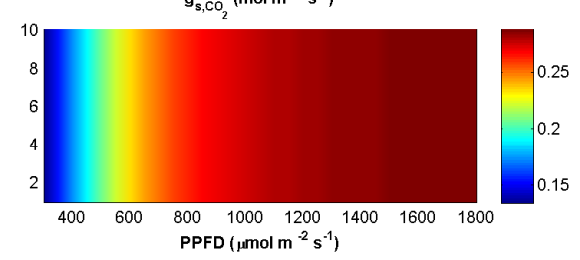

Figure Appendix C.1: Modeled $f_{e}, f_{c}$ and $g_{s, \mathrm{CO}_{2}}$ as a function of $U$ and PPFD for well-watered soil condition $(\lambda=0.001$ $\left.\mu \mathrm{mol} \mathrm{mol}{ }^{-1} \mathrm{kPa}^{-1}\right)$ and small evaporative demand $(R H=60 \%)$. 


\section{Appendix D. Ball-Berry and Leuning semi-empirical models}

Two formulations of $g_{s, \mathrm{CO}_{2}}$ - the Ball-Berry (BB) (Ball et al., 1987) and the Leuning models (LEU) (Leuning, 1995) are commonly adopted in climate (Sellers et al., 1995, 1996) or biosphere-atmosphere (Baldocchi and Meyers, 1998; Juang et al., 2008; Lai et al., 2000; Siqueira and Katul, 2002) gas exchange models. They are represented as:

$$
g_{s, \mathrm{CO}_{2}}=m \frac{f_{c}}{c_{a}-\Gamma^{*}} F
$$

where $m$ 's (i.e., respectively denoted as $m_{B B}$ and $m_{L E U}$ for BB and LEU) are the empirical fitting parameters and the reduction functions $F$ 's are respectively $F_{B B}=R H$ and $F_{L E U}=$ $\left(1+\mathrm{VPD} / D_{0}\right)^{-1}$ where $D_{0}$ is a normalizing constant for BB and LEU.

The BB and LEU models are employed as alternatives to close the system of equations discussed in Section 2 instead of the optimality hypothesis so as to further assess whether a nonmonotonic $f_{e}-U$ relation is robust to such optimality condition. To illustrate, it is assumed that $\Gamma^{*}=50 \mu \mathrm{mol} \mathrm{mol}{ }^{-1}, D_{0}=3 \mathrm{kPa}$ and the same conditions for the four scenarios discussed in Section 3.1. The empirical parameters $m$ 's are estimated by setting $m_{B B}=\left[R H\left(1-c_{i} / c_{a}\right)\right]^{-1}$ and $m_{L E U}=\left(1+\mathrm{VPD} / D_{0}\right)\left(1-\Gamma^{*} / c_{a}\right)\left(1-c_{i} / c_{a}\right)^{-1}$ (Katul et al., 2000). The computed $c_{i} / c_{s}$ from the optimality model under high PPFD and high wind conditions (approximating well coupled state) is adopted when determining the $m$ 's in BB and LEU so as to ensure their equivalence to optimality theory for such conditions. Next, the $f_{e}$ as a function of $U$ and PPFD computed by BB and LEU are shown in Figure Appendix D.1. Theses results maintain similar patterns when compared to the optimality model for stomatal conductance (see Figure 3-5) such as the transitions of the modeled $f_{e}$ trends with increasing $U$. It is safe to state that the conclusions drawn from the modeling work here about the non-monotonic response of $f_{e}$ to $U$ is not sensitive to the precise stomatal closure approximation used to model the stomatal conductance. This completes the objective of the appendix. 

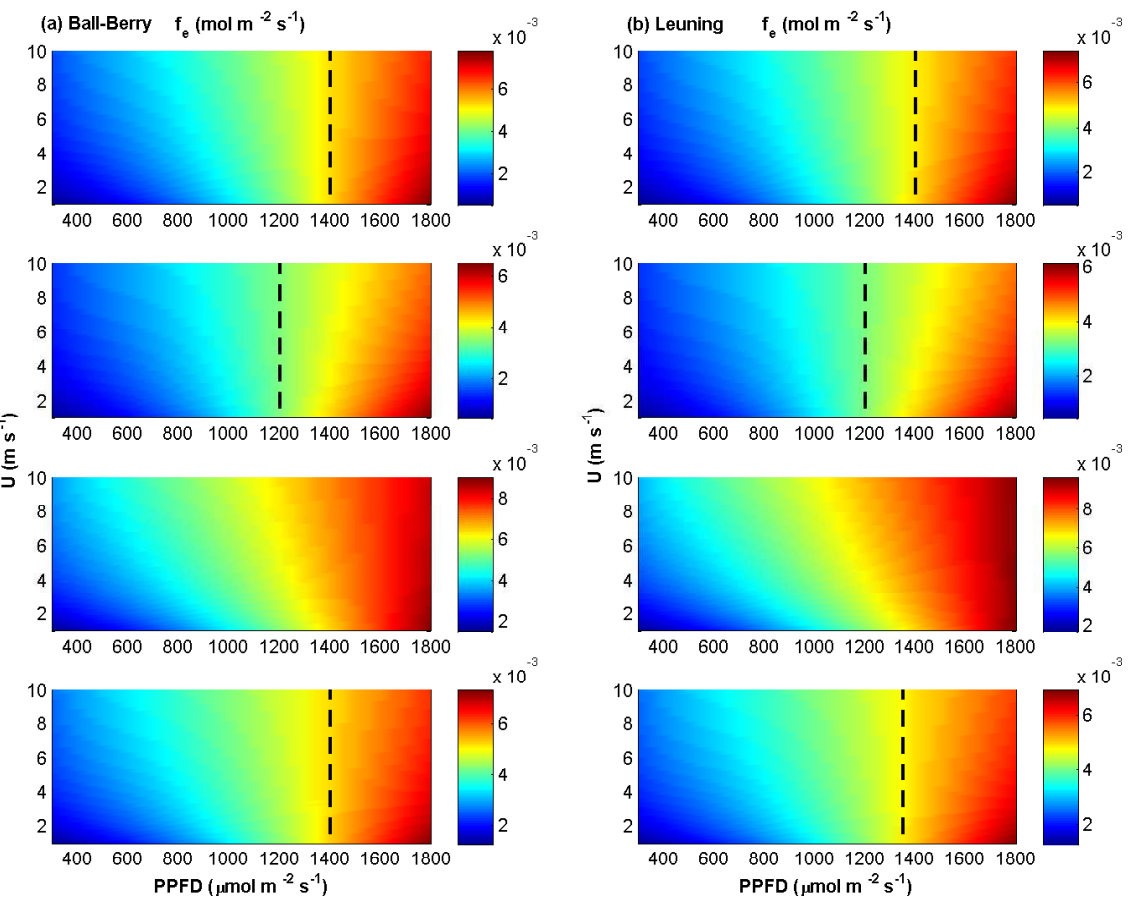

Figure Appendix D.1: Modeled $f_{e}$ using (a) Ball-Berry and (b) Leuning models assuming the same conditions for the four scenarios discussed in Section 3.1. Well-watered soil conditions with small evaporative demand, water-stressed soil conditions with small evaporative demand, large evaporative demand under well-watered soil moisture conditions and large evaporative demand under water-stressed soil moisture conditions are respectively shown from top to bottom panels. Note that the transition PPFD for the sign reversal of $\partial f_{e} / \partial U$ is represented by broken lines. 


\section{Appendix E. Sensitivity analysis}

A sensitivity index $I$ is defined as:

$$
I=\sqrt{\frac{1}{N} \sum_{i=1}^{N}\left(O-O_{0}\right)_{i}^{2}} \times 100
$$

698

699

700

701

where $O_{0}$ is the model output calculated from the pre-specified input variables (i.e., $V_{c m a x, 25}=50$ $\mu \mathrm{mol} \mathrm{m} \mathrm{m}^{-2} \mathrm{~s}^{-1}$ and $\left.J_{\max , 25}=100 \mu \mathrm{mol} \mathrm{m}^{-2} \mathrm{~s}^{-1}\right), O$ is the model output calculated by altering input variables according to data reported elsewhere (Wang et al., 1996; Wullschleger, 1993) and $N$ is the number of data points. The index $I$ is selected here to assess the sensitivity of the model output due to the model parameter variability. The uncertainties of the input variables for the proposed model are listed in Table Appendix E.1. Table Appendix E.1 shows that the uncertainties for the two physiological model parameters have minor impact on the model results 
Table Appendix E.1: Sensitivity index $I$ for the pre-specified input variables. 


\section{References}

Baldocchi, D., Falge, E., Gu, L., Olson, R., Hollinger, D., Running, S., Anthoni, P., Bernhofer, C., Davis, K., Evans, R., et al., 2001. Fluxnet: A new tool to study the temporal and spatial variability of ecosystem-scale carbon dioxide, water vapor, and energy flux densities. Bulletin of the American Meteorological Society 82, 2415-2434.

Baldocchi, D., Meyers, T., 1998. On using eco-physiological, micrometeorological and biogeochemical theory to evaluate carbon dioxide, water vapor and trace gas fluxes over vegetation: a perspective. Agricultural and Forest Meteorology 90, 1-25.

Ball, J.T., Woodrow, I.E., Berry, J.A., 1987. A model predicting stomatal conductance and its contribution to the control of photosynthesis under different environmental conditions, in: Progress in photosynthesis research. Springer, pp. 221-224.

Bernacchi, C.J., Singsaas, E.L., Pimentel, C., Portis Jr, A.R., Long, S.P., 2001. Improved temperature response functions for models of rubiscolimited photosynthesis. Plant, Cell and Environment 24, 253-259.

Berninger, F., Hari, P., 1993. Optimal regulation of gas exchange: evidence from field data. Annals of Botany 71, $135-140$.

Betts, R., Boucher, O., Collins, M., Cox, P., Falloon, P., Gedney, N., Hemming, D., Huntingford, C., Jones, C., Sexton, D., Webb, M., 2007. Projected increase in continental runoff due to plant responses to increasing carbon dioxide. Nature 448, 1037-1041.

Bladon, K.D., Silins, U., Landhäusser, S.M., Lieffers, V.J., 2006. Differential transpiration by three boreal tree species in response to increased evaporative demand after variable retention harvesting. Agricultural and Forest Meteorology 138, 104-119. doi:10.1016/j.agrformet.2006.03.015.

Caird, M.A., Richards, J.H., Donovan, L.A., 2007. Nighttime stomatal conductance and transpiration in $\mathrm{C}_{3}$ and $\mathrm{C}_{4}$ plants. Plant Physiology 143, 4-10.

Campbell, G.S., Norman, J., 1998. An introduction to environmental biophysics. Springer, New York.

Campbell-Clause, J.M., 1998. Stomatal response of grapevines to wind. Animal Production Science 38, 77-82.

Chu, C.R., Hsieh, C.I., Wu, S.Y., Phillips, N.G., 2009. Transient response of sap flow to wind speed. Journal of Experimental Botany 60, 249-255.

Cowan, I., Farquhar, G., 1977. Stomatal function in relation to leaf metabolism and environment. In: Integration of activity in the higher plant. Symposia of the Society for Experimental Biology. volume 31. Cambridge University Press, Cambridge.

Cox, P., Betts, R., Jones, C., Spall, S., Totterdell, I., 2000. Acceleration of global warming due to carbon-cycle feedbacks in a coupled climate model. Nature 408, 184-187.

Damour, G., Simonneau, T., Cochard, H., Urban, L., 2010. An overview of models of stomatal conductance at the leaf level. Plant, Cell and Environment 33, 1419-1438.

Dawson, T.E., Burgess, S.S.O., Tu, K.P., Oliveira, R.S., Santiago, L.S., Fisher, J.B., Simonin, K.A., Ambrose, A.R., 2007. Nighttime transpiration in woody plants from contrasting ecosystems. Tree Physiology 27, 561-575.

DeLucia, E.H., Heckathorn, S.A., 1989. The effect of soil drought on water-use efficiency in a contrasting Great Basin desert and Sierran montane species. Plant, Cell and Environment 12, 935-940.

Dixon, M., Grace, J., 1984. Effect of wind on the transpiration of young trees. Annals of Botany 53, 811-819.

Duursma, R.A., Payton, P., Bange, M.P., Broughton, K.J., Smith, R.A., Medlyn, B.E., Tissue, D.T., 2013. Near-optimal response of instantaneous transpiration efficiency to vapour pressure deficit, temperature and $\left[\mathrm{CO}_{2}\right]$ in cotton $($ Gossypium hirsutum L.). Agricultural and Forest Meteorology 168, 168-176.

Farquhar, G.D., von Caemmerer, S., Berry, J.A., 1980. A biochemical model of photosynthetic $\mathrm{CO}_{2}$ assimilation in leaves of $\mathrm{C}_{3}$ species. Planta 149, 78-90.

Gates, D.M., 1968. Transpiration and leaf temperature. Annual Review of Plant Physiology 19, 211-238.

Gedney, N.and Cox, P., Betts, R., Boucher, O., Huntingford, C., Stott, P., 2006. Detection of a direct carbon dioxide effect in continental river runoff records. Nature 439, 835-838.

Givnish, T.J., Vermeij, G.J., 1976. Sizes and shapes of liane leaves. American Naturalist, 743-778.

Grace, J., 1974. The effect of wind on grasses 1. cuticular and stomatal transpiration. Journal of Experimental Botany $25,542-551$.

Grace, J., Malcolm, D.C., Bradbury, I.K., 1975. The effect of wind and humidity on leaf diffusive resistance in Sitka spruce seedlings. Journal of Applied Ecology , 931-940.

Grace, J., Russell, G., 1982. The effect of wind and a reduced supply of water on the growth and water relations of Festuca arundinacea Schreb. Annals of Botany 49, 217-225.

Granier, A., 1987. Evaluation of transpiration in a Douglas-fir stand by means of sap flow measurements. Tree physiology 3, 309-320

Green, S.R., McNaughton, K.G., Greer, D.H., McLeod, D.J., 1995. Measurement of the increased PAR and net allwave radiation absorption by an apple tree caused by applying a reflective ground covering. Agricultural and Forest Meteorology 76, 163-183. 
Gutiérrez, M.V., Meinzer, F.C., Grantz, D.A., 1994. Regulation of transpiration in coffee hedgerows - covariation of environmental variables and apparent responses of stomata to wind and humidity. Plant Cell and Environment 17, 1305-1313. doi:10.1111/j.1365-3040.1994.tb00532.x.

Hari, P., Mäkelä, A., Korpilahti, E., Holmberg, M., 1986. Optimal control of gas exchange. Tree physiology 2, 169-175.

Huang, L., Zhang, Z.S., Li, X.R., 2010. Sap flow of Artemisia ordosica and the influence of environmental factors in a revegetated desert area: Tengger Desert, China. Hydrological processes 24, 1248-1253.

Hunt, L.A., Impens, I.I., Lemon, E.R., 1967. Preliminary wind tunnel studies of the photosynthesis and evapotranspiration of forage stands. Crop Science 7, 575-578.

Jones, H.G., 1992. Plants and microclimate: A quantitative approach to environmental plant physiology. Cambridge University Press, Cambridge.

Juang, J., Katul, G.G., Siqueira, M., Stoy, P., McCarthy, H., 2008. Investigating a hierarchy of eulerian closure models for scalar transfer inside forested canopies. Boundary-Layer Meteorology 128, 1-32.

Katul, G., Ellsworth, D., Lai, C.T., 2000. Modelling assimilation and intercellular $\mathrm{CO}_{2}$ from measured conductance: a synthesis of approaches. Plant, Cell and Environment 23, 1313-1328.

Katul, G.G., Mahrt, L., Poggi, D., Sanz, C., 2004. One- and two-equation models for canopy turbulence. Boundary-Layer Meteorology 113, 81-109.

Katul, G.G., Manzoni, S., Palmroth, S., Oren, R., 2010. A stomatal optimization theory to describe the effects of atmospheric $\mathrm{CO}_{2}$ on leaf photosynthesis and transpiration. Annals of Botany 105, 431-442.

Katul, G.G., Oren, R., Manzoni, S., Higgins, C., Parlange, M.B., 2012. Evapotranspiration: A process driving mass transport and energy exchange in the soil-plant-atmosphere-climate system. Reviews of Geophysics 50. doi:Artn $\operatorname{Rg} 3002$ Doi 10.1029/2011rg000366.

Katul, G.G., Schieldge, J., Hsieh, C.I., Vidakovic, B., 1998. Skin temperature perturbations induced by surface layer turbulence above a grass surface. Water Resources Research 34, 1265-1274.

Kim, D., Oren, R., Oishi, A.C., Hsieh, C.I., Phillips, N., Novick, K.A., Stoy, P.C., 2014. Sensitivity of stand transpiration to wind velocity in a mixed broadleaved deciduous forest. Agricultural and Forest Meteorology 187, 62-71. doi:10.1016/j.agrformet.2013.11.013.

Kitaya, Y., Shibuya, T., Yoshida, M., Kiyota, M., 2004. Effects of air velocity on photosynthesis of plant canopies under elevated $\mathrm{CO}_{2}$ levels in a plant culture system. Advances in Space Research 34, 1466-1469.

Konrad, W., Roth-Nebelsick, A., Grein, M., 2008. Modelling of stomatal density response to atmospheric $\mathrm{CO}_{2}$. Journal of Theoretical Biology 253, 638-658.

Lai, C., Katul, G., Oren, R., Ellsworth, D., Schäfer, K., 2000. Modeling co2 and water vapor turbulent flux distributions within a forest canopy. Journal of Geophysical Research: Atmospheres 105, 26333-26351.

Launiainen, S., Katul, G.G., Kolari, P., Vesala, T., Hari, P., 2011. Empirical and optimal stomatal controls on leaf and ecosystem level $\mathrm{CO}_{2}$ and $\mathrm{H}_{2} \mathrm{O}$ exchange rates. Agricultural and Forest Meteorology 151, 1672-1689.

Leuning, R., 1995. A critical appraisal of a combined stomatal-photosynthesis model for $\mathrm{C}_{3}$ plants. Plant, Cell and Environment 18, 339-355.

Liu, F., Andersen, M.N., Jacobsen, S.E., Jensen, C.R., 2005. Stomatal control and water use efficiency of soybean (Glycine max L. Merr.) during progressive soil drying. Environmental and Experimental Botany 54, 33-40.

Mäkelä, A., Berninger, F., Hari, P., 1996. Optimal control of gas exchange during drought: Theoretical analysis. Annals of Botany 77, 461-467. doi:DOI 10.1006/anbo.1996.0056.

Manzoni, S., Vico, G., Katul, G., Fay, P.A., Polley, W., Palmroth, S., Porporato, A., 2011. Optimizing stomatal conductance for maximum carbon gain under water stress: a meta-analysis across plant functional types and climates. Functional Ecology 25, 456-467. doi:DOI 10.1111/j.1365-2435.2010.01822.x.

Manzoni, S., Vico, G., Palmroth, S., Porporato, A., Katul, G., 2013. Optimization of stomatal conductance for maximum carbon gain under dynamic soil moisture. Advances in Water Resources 62, 90-105.

Martin, E.V., Clements, F.E., 1935. Studies of the effect of artificial wind on growth and transpiration in Helianthus annuus. Plant physiology 10, 613 .

Masle, J., Farquhar, G.D., 1988. Effects of soil strength on the relation of water-use efficiency and growth to carbon isotope discrimination in wheat seedlings. Plant Physiology 86, 32-38.

Medlyn, B.E., Dreyer, E., Ellsworth, D., Forstreuter, M., Harley, P.C., Kirschbaum, M.U.F., Le Roux, X., Montpied, P., Strassemeyer, J., Walcroft, A., 2002. Temperature response of parameters of a biochemically based model of photosynthesis. II. a review of experimental data. Plant, Cell and Environment 25, 1167-1179.

Monteith, J.L., 1965. Evaporation and environment, in: Symposia of the Society for Experimental Biology, p. 205224

Mott, K.A., Parkhurst, D.F., 1991. Stomatal responses to humidity in air and helox. Plant, Cell and Environment 14, 509-515.

Novick, K.A., Oren, R., Stoy, P.C., Siqueira, M.B.S., Katul, G.G., 2009. Nocturnal evapotranspiration in eddy-covariance records from three co-located ecosystems in the Southeastern U.S.: Implications for annual fluxes. Agricultural and Forest Meteorology 149, 1491-1504.

Prentice, I.C., Meng, T., Wang, H., Harrison, S.P., Ni, J., Wang, G., 2011. Evidence of a universal scaling relationship 
for leaf $\mathrm{CO}_{2}$ drawdown along an aridity gradient. New Phytologist 190, 169-180

824 Sellers, P., Bounoua, L., Collatz, G., Randall, D., Dazlich, D., Los, S., Berry, J., Fung, I., Tucker, C., Field, C., Jensen, T., 1996. Comparison of radiative and physiological effects of doubled atmospheric $\mathrm{CO}_{2}$ on climate. Science 271, 1402 .

827 Sellers, P., Meeson, B., Hall, F., Asrar, G., Murphy, R., Schiffer, R., Bretherton, F., Dickinson, R., Ellingson, R., Field, C., Huemmrich, K., Justice, C., Melack, J., Roulet, N., Schimel, D., Try, P., 1995. Remote sensing of the land surface for studies of global change: Modelsalgorithmsexperiments. Remote Sensing of Environment 51, 3-26.

30 Siqueira, M., Katul, G., 2002. Estimating heat sources and fluxes in thermally stratified canopy flows using higher-order closure models. Boundary-Layer Meteorology 103, 125-142.

832 Vico, G., Manzoni, S., Palmroth, S., Weih, M., Katul, G., 2013. A perspective on optimal leaf stomatal conductance under co 2 and light co-limitations. Agricultural and forest meteorology 182, 191-199.

Volpe, V., Manzoni, S., Marani, M., Katul, G., 2011. Leaf conductance and carbon gain under salt-stressed conditions. Journal of Geophysical Research-Biogeosciences 116. doi:Artn G04035 Doi 10.1029/2011jg001848.

Wang, K.Y., Kellomaki, S., Laitinen, K., 1996. Acclimation of photosynthetic parameters in Scots pine after three years exposure to elevated temperature and $\mathrm{CO}_{2}$. Agricultural and Forest Meteorology 82, 195-217. doi:Doi 10.1016/01681923(96)02329-5.

Wullschleger, S.D., 1993. Biochemical limitations to carbon assimilation in $\mathrm{C}_{3}$ plants-a retrospective analysis of the $\mathrm{A} / \mathrm{C}_{i}$ curves from 109 species. Journal of Experimental Botany 44, 907-920.

841 Zalesny Jr, R.S., Wiese, A.H., Bauer, E.O., Riemenschneider, D.E., 2006. Sapflow of hybrid poplar (Populus nigra L. P. 